Review

\title{
Invasive Fungal Infections in the ICU: How to Approach, How to Treat
}

\section{Elisabeth Paramythiotou *, Frantzeska Frantzeskaki, Aikaterini Flevari, Apostolos Armaganidis and George Dimopoulos}

Department of Critical Care Medicine, University Hospital ATTIKON, Medical School of Athens, Haidari 12462, Greece

* Author to whom correspondence should be addressed; E-Mail: lparamyth61@hotmail.com; Tel.: +30-210-5832184; Fax: +30-210-5326385.

Received: 1 November 2013; in revised form: 3 January 2014 / Accepted: 9 January 2014 /

Published: 17 January 2014

\begin{abstract}
Invasive fungal infections are a growing problem in critically ill patients and are associated with increased morbidity and mortality. Most of them are due to Candida species, especially Candida albicans. Invasive candidiasis includes candidaemia, disseminated candidiasis with deep organ involvement and chronic disseminated candidiasis. During the last decades rare pathogenic fungi, such as Aspergillus species, Zygomycetes, Fusarium species and Scedosporium have also emerged. Timely diagnosis and proper treatment are of paramount importance for a favorable outcome. Besides blood cultures, several laboratory tests have been developed in the hope of facilitating an earlier detection of infection. The antifungal armamentarium has also been expanded allowing a treatment choice tailored to individual patients' needs. The physician can choose among the old class of polyenes, the older and newer azoles and the echinocandins. Factors related to patient's clinical situation and present co-morbidities, local epidemiology data and purpose of treatment (prophylactic, pre-emptive, empiric or definitive) should be taken into account for the appropriate choice of antifungal agent.
\end{abstract}

Key words: Candida infections; intensive care unit; fungi 


\section{Introduction}

Great advances in contemporary medicine and especially in critical care achieved during the last decades have contributed not only to longer survival of patients, but also to the increasing incidence of opportunistic infections caused by fungi. Complex medical and surgical problems, disruption of natural barriers, multiple invasive procedures and prolonged antibiotic treatment are some of the factors contributing to the alarming increase of fungal infections in the Intensive Care Unit (ICU) setting [1,2]. The leading fungal infection is candidaemia. In 2007 the results of EPIC II study including 1,265 ICUs in 75 countries revealed that $19 \%$ of pathogens isolated in ICU patients were fungi [3]. Candida species (spp) were predominantly isolated (17\%) followed by Aspergillus species. Candidaemia is associated with a high mortality and increased length of hospital stay and cost [4,5]. High attributable mortality may be due to delayed diagnosis and treatment, development of resistance or severity of illness. The purpose of the present review is to provide a practical approach to diagnosis and treatment of invasive fungal infections in the critically ill.

\section{Candida Invasive Disease}

Candida species are ubiquitous and constitute part of the normal human flora. Only a small percentage of the identified species cause disease in humans. Candida spp. is responsible for an extremely large spectrum of diseases [6,7]. Invasive Candida infections include candidaemia with or without endopthalmitis; disseminated haematogeneous infections; involvement of a single deep organ site (e.g. peritonitis, other abdominal infections, meningitis and infective endocarditis) and chronic hepatosplenic candidiasis mostly in haematological patients [8]. Source of Candida infection can be endogenous (gastro-intestinal flora or mucocutaneous colonisation) and exogenous (hands of healthworkers, contaminated infusates) even leading to local outbreaks [9]. Existing epidemiological data usually originate from candidaemia [10].

\section{Incidence, Trends and Mortality}

Candida bloodstream infections (BSIs) constitute the vast majority of nosocomial fungal infections. In a large nationwide surveillance study in United States (SCOPE) Candida spp were ranked fourth among the hospital-acquired BSIs (9\%) [11]. The majority of infections (51\%) were noticed in ICU [11]. Almirante et al showed an incidence of 4.3/100,000 population in Spain while in a study conducted in Iceland a rise from 4.3 to 5.7 cases per/100,000 population was noticed [12,13]. In another study including 106 institutions in seven European countries, the rates of candidaemia ranged from 0.20 to $0.38 / 1,000$ admissions [14]. Limited data on the incidence of invasive Candida infections (ICI) in the critically ill are available. In an Australian study of ICU-acquired BSIs, Candida species were ranked fourth (15.5\%) while according to Meyer et al. the incidence of primary nosocomial candidaemia in 682 German ICUs remained stable in a 5-year period [15,16]. In a recent study from Italy a total of 105 episodes occurred in an 18-month period with 16.5 cases per 1,000 admissions caused by yeasts and 2.3 cases per 1,000 admissions caused by filamentous fungi [17]. In a large prospective multicenter study conducted in French ICUs fungi were identified in $3.2 \%$ of patients with microbiologically documented infections [18]. Finally in an International Cohort Study (EUROBACT) 
of ICU-associated BSIs, candidaemia was ranked third below Gram-negative and Gram-positive isolates [19]. In a total of 1317 microorganisms, 98 (7,4\%) were due to fungi and most of them due to Candida species [19]. The disparity between the results of studies may be explained by differences in demographic characteristics, variations in healthcare practice, difference in presence of co-morbidities and populations studied. Nevertheless the true incidence of invasive candidiasis may be higher not only due to the fact that the percentage of positive cultures lies between 30 and $50 \%$ but also because of the difficulty in diagnosing invasive candidiasis without candidaemia [20,21].

Candida BSIs are a well-recognized cause of morbidity and mortality among the critically ill. Though the crude mortality varies between studies, most authors report high percentages $(39 \%-60 \%)$ and excess financial burden [11,22]. Attributable mortality is considered a better index to estimate the impact of ICI though it is more difficult to validate. A major difficulty is distinguishing between mortality attributed to candidaemia and mortality caused by the severe underlying disease. In a systematic review about candidaemia-associated mortality Falagas et al. included seven studies with attributable mortality ranging between 5 and $71 \%$. For six of them a considerable difference in mortality between cases and controls was observed. Moreover the length of stay and hospitalization cost was significantly higher than that of controls [23]. If candidaemia is manifested with signs of sepsis or septic shock the associated mortality and financial burden are further increased [24].

\section{The Changing Epidemiology of Candida spp.}

Among Candida species which are pathogenic for humans, Candida albicans is the most frequently recognized followed by $C$. parapsilosis, C. glabrata and C. tropicalis [25]. Species infrequently encountered include C. krusei, C. dublinensis, C. guillermondi, C. kefir, C. lusitaniae, and C. rugosa. Nevertheless the list of species formerly considered as "non-pathogenic" is expanding with the increase in the number of vulnerable population and the ability of the laboratory to isolate new species. During the last decades a shift to non-albicans species has been noted [26]. According to data provided by an International Surveillance Program, ARTEMIS DISK, the distribution of Candida species in a 6-year period has changed with $C$. albicans decreasing by $10 \%$ though still remaining the most common isolated species [27]. This changing spectrum has been partly explained by the increasing prophylactic use of fluconazole though this hypothesis has not been confirmed by all investigators [28]. The increased proportion of non-albicans species has been also observed in critically ill patients with considerable differences in the percentage of albicans vs non-albicans spp [23]. In an Italian study $40 \%$ of the fungaemia episodes were due to C. albicans, followed by C. parapsilosis (23\%), C. glabrata (15\%), C. tropicalis (9\%) and other species (13\%) [29]. In a prospective national study conducted in 180 French ICUs $C$. albicans accounted for $57 \%$ of blood isolates followed by $C$. glabrata (16.7\%), C. parapsilosis (7.5\%), C. krusei (5.2\%) and C. tropicalis (4.9\%) [30]. Several risk factors have been associated with the presence of non-albicans species (NAS). In a case-comparator study Chow et al. showed that fluconazole exposure, presence of a central venous catheter and mean number of antibiotics per day were associated with an increased risk of BSIs due to NAS compared to C. albicans while in another study use of medical devices, steroids receipt and pre-existing candiduria were the risk factors associated with the presence of NAS [31,32]. Moreover every Candida species has its separate characteristics [7,10,33-35] (Table 1). The shift to non-Candida spp. is important 
because some of these species are resistant to fluconazole or other antifungal agents. Awareness of risk factors for the presence of NAS, rapid species identification and antifungal susceptibility testing are required for the proper and timely treatment of these infections.

Table 1. Main characteristics and factors affecting the emergence of Candida non-albicans spp [7,10,33-35].

\begin{tabular}{|c|c|}
\hline C. glabrata & $\begin{array}{l}\text { Most common in elderly patients } \\
\text { Most common in malignancies } \\
\text { Geographic variation } \\
\text { Associated to the use of specific antibiotics, (piperacillin/tazobactam, vancomycin) } \\
\text { Common in patients under TPN and with CVC } \\
\text { Isolation system } \\
\text { Solid organ transplantation } \\
\text { Fluconazole exposure }\end{array}$ \\
\hline C. parapsilosis & $\begin{array}{l}\text { Nosocomial outbreaks } \\
\text { Formation of biofilms in CVC } \\
\text { Implanted devices } \\
\text { TPN } \\
\text { Less susceptible to echinocandins } \\
\text { The second most common isolated strain in children }\end{array}$ \\
\hline C. tropicalis & $\begin{array}{l}\text { Haematological malignancies } \\
\text { Neutropenia }\end{array}$ \\
\hline C. krusei & $\begin{array}{l}\text { Use of piperacillin/tazobactam, vancomycin } \\
\text { Innate resistance to fluconazole } \\
\text { Haematological malignancies } \\
\text { Neutropenia } \\
\text { Recent gastrointestinal surgery } \\
\text { Fluconazole exposure }\end{array}$ \\
\hline C. guiillermondi & $\begin{array}{l}\text { Less susceptible to echinocandins } \\
\text { Less susceptible to fluconazole } \\
\text { Intravascular catheters }\end{array}$ \\
\hline
\end{tabular}

$\mathrm{CVC}=$ Central venous catheters, $\mathrm{TPN}=$ Total Parenteral Nutrition.

\section{Laboratory Diagnostic Methods}

In the critically ill patient the diagnosis of invasive candidiasis (IC) is not an easy task because signs and symptoms vary from minimal to dramatic while existing diagnostic procedures present several drawbacks. Blood cultures (BCs) remain the cornerstone of diagnosis but they have suboptimal sensitivity $(30 \%-50 \%)$ and need long incubation time [21]. Moreover in deep-seated candidiasis or in patients under fluconazole prophylaxis, BCs are often negative [36,37]. Newer culture methods have raised the sensitivity of Candida detection to almost $70 \%$, but they require a minimum of 24 to $48 \mathrm{~h}$ to become positive and thus their result may come late in the course of the infection [38].

In order to make timely diagnosis more feasible, several serological markers have been developed. These tests consist of the detection of various agents, components of the fungal cell wall such as the mannan and 1,3- $\beta$-D-glucan tests whereas antibodies against the mannan antigen (anti-mannan) have also been developed [21,39-41]. For the detection of mannan antigen two methods have been 
described: a latex agglutination test (Pastorex-Candida; Biorad, Biorad laboratories GmBH); and an enzyme-linked immunosorbent assay (ELISA)(Platelia-Candida; Biorad). Both methods have equal specificity $(90 \%-100 \%)$ in diagnosing candidaemia $[38,42]$ but ELISA has superior sensitivity, ranging between $30 \%-60 \%$, depending on study population, diagnostic cut-off points and Candida species under consideration, being higher for C. albicans [42-44]. In high risk patients, performing the test two to three times per week is highly recommended, since its circulation in the bloodstream is intermittent $[21,38]$. Combined detection of mannan and anti-mannan antibodies in blood (ELISA) offers higher sensitivity $(80 \%-100 \%)$ but concurrent drop in specificity $(84 \%)[39,42]$. The detection of 1,3- $\beta$-D-glucan (BG) (Fungitell Assay; Cape Cod, MA, USA), which is a pan-fungal marker (except for Mucorales and Cryptococcus), demonstrates variable sensitivity depending on the cut-off diagnostic value and the Candida species under consideration [40,41,44]. One single positive test is only suggestive of Candida infection and it must be interpreted with caution due to false positive results from albumin and/or immunoglobulin administration, haemodialysis or Gram-positive bacteraemia $[38,45]$. A negative $\mathrm{BG}$ test is associated with high negative predictive value $(>90 \%)$ and can be used to rule out IC. In a recent study by Posteraro et al. the BG test exhibited excellent positive $(72,2 \%)$ and negative $(98,7 \%)$ predictive values in critically ill patients [46]. An indirect immunofluorescence assay has also been developed for the detection of antibodies (IgG) against $C$. albicans (C. albicans germ-tube antibodies, CAGTA, Vircell, Granada, Spain) showing 77\%-89\% sensitivity and $91 \%-100 \%$ specificity $[45,47]$. Though excellent for monitoring therapy, it cannot discriminate BSIs among Candida species and it has not been validated in the critical care setting.

Additionally nucleic acid-based detection methods (real-time polymerase chain reaction) have been developed for the detection of Candida infection [36,48,49]. According to Ngyuen et al., both realtime PCR and BCs have comparable sensitivities in diagnosing candidaemia (60\%) but PCR is invaluable in diagnosing deep-seated candidiasis with negative BCs (sensitivity $88 \%$ for PCR vs $17 \%$ for BCs) [36]. Moreover PCR performance is not influenced by the addition of antifungal therapy [36]. Data concerning the use of PCR in the critical care setting are limited. McMullan et al. tested three realtime PCR assays for the detection of Candida spp in non-neutropenic critically ill patients with candidaemia, showing excellent sensitivity (90.9\%) and specificity (100\%) [48].

Finally several recently introduced diagnostic tools include: (a) matrix- assisted laser desorption ionization - time of flight mass spectrometry (MALDI-TOF MS). The test seems a rapid and reliable tool for the identification of yeasts and yeast-like fungi [50]; (b) a commercial assay allowing the molecular detection of fungi in blood (Lightcycler Septofast-Test, Roche Diagnostics GmBH, Mannheim, Germany) and (c) a commercial assay based on fluorescence in situ hybridization (PNA FISH). This method is a rapid way to differentiate among the usually isolated Candida species in blood provided that blood cultures have developed Candida spp [51]. In a recent study, comparison between MALDI-TOF and PNA-FISH for yeasts showed that the PNA FISH assay had a 100\% agreement with the result obtained by MALDI-TOF MS [52].

\section{Risk Factor Assessment}

Invasive Candida infection leads to increased mortality in case of treatment delay. The lack of methods with a high sensitivity and specificity for the timely diagnosis of IC created the need for the 
identification of risk factors and evaluation methods in order to ensure timely treatment even in the absence of laboratory evidence of infection. These risk factors have been described in many studies [53-56] and they are summarized in Table 2.

Table 2. Factors leading to Candida albicans invasive infections in ICU patients [53-56].

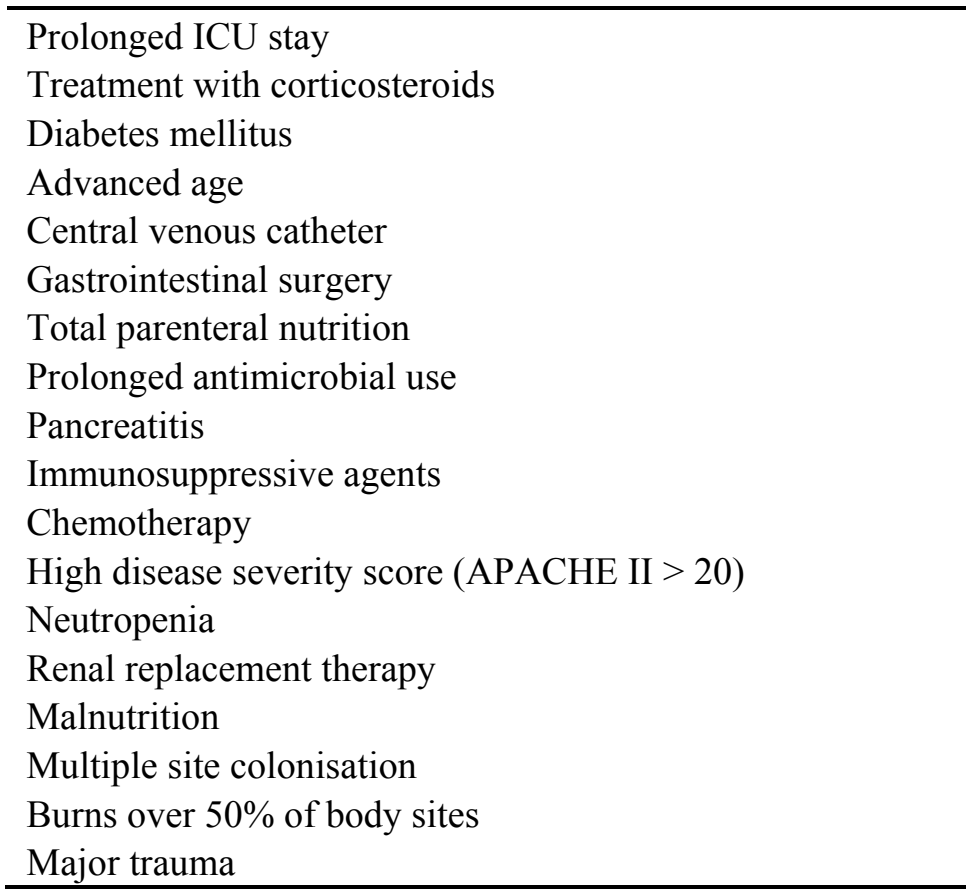

Fungal colonisation has been associated with the development of IC, yet according to recent data, a small proportion (3\%-25\%) of colonised patients subsequently develop invasive disease [57,58]. Due to the time-consuming nature of all the aforementioned laboratory methods and since in IC immediate antifungal drug therapy is mandatory, several researchers have investigated Candida colonisation patterns in combination with the established risk factors of Table 2, in order to identify specific patient groups who might benefit from antifungal prophylaxis/therapy. These "risk factors" expressed as Candida Prediction Rules have been established in many studies [56,58-64] and they are summarized in Table 3.

Table 3. Candida Prediction Rules.

\begin{tabular}{|c|c|c|}
\hline Authors & Aims and Criteria & Factors and Prediction Rule \\
\hline Leon $[56]$ & Surgical patients & $\begin{array}{l}\text { "Candida score" } \\
\text { Factors leading to invasive candidiasis development include } \\
\text { multifocal colonisation, surgery on ICU admission, severe } \\
\text { sepsis, TPN. } \\
\text { A "Candida score" > } 2.5 \text { selects the non-neutropenic ICU } \\
\text { patients who might benefit from early antifungal treatment }\end{array}$ \\
\hline Agvald-Öhman [58] & $\begin{array}{l}\text { To identify patients at risk of IC } \\
\text { among those with a length of ICU } \\
\text { stay of at least } 7 \text { days }\end{array}$ & $\begin{array}{l}\text { Candida colonisation index } \geq 0.8 \text { and recent extensive } \\
\text { gastroabdominal surgery }\end{array}$ \\
\hline Pittet [59] & $\begin{array}{l}\text { Surgical and neonatal ICUs } \\
\text { To identify patients in surgical } \\
\text { and neonatal ICUs at increased } \\
\text { risk of subsequent infection. }\end{array}$ & $\begin{array}{l}C C I=\text { Candida } \text { Colonisation Index } \\
\text { Patients with } C C I \geq 0.5 \text { at high risk. }\end{array}$ \\
\hline
\end{tabular}


Table 3. Cont.

\begin{tabular}{|c|c|c|}
\hline Authors & Aims and Criteria & Factors and Prediction Rule \\
\hline Dupont [60] & Patients with severe peritonitis & $\begin{array}{l}\text { Presence of at least three of female sex, cardiovascular failure, } \\
\text { upper gastrointestinal tract origin, ongoing antimicrobial } \\
\text { therapy predicts yeast isolation in the peritoneal fluid }\end{array}$ \\
\hline Ostrosky-Zeichner [61] & $\begin{array}{l}\text { To identify patients at increased } \\
\text { risk of IC in medical and surgical } \\
\text { ICUs }\end{array}$ & $\begin{array}{l}\text { Any systemic antibiotic (days 1-3) } \\
\text { OR } \\
\text { CVC (days 1-3) } \\
\text { AND at least TWO of the following: } \\
T P N(\text { days 1-3), any dialysis (days 1-3), any major surgery } \\
\text { (days 7-0), pancreatitis (days 7-0), steroid use (days -7-3). } \\
\text { other immunosuppressive drug (days 7-0) }\end{array}$ \\
\hline Hermsen [62] & $\begin{array}{l}\text { Due to the high Negative } \\
\text { Predictive Value, the rule applies } \\
\text { best to identify patients who are } \\
\text { LEAST likely to benefit from } \\
\text { antifungal therapy }\end{array}$ & $\begin{array}{l}\text { Current systemic broad-spectrum antibiotic use, CVC, TPN, } \\
\text { abdominal surgery within last } 7 \text { days, steroid use, hospital LOS }\end{array}$ \\
\hline Paphitou [63] & $\begin{array}{l}\text { To identify patients at increased } \\
\text { risk of invasive candidiasis in } \\
\text { surgical ICUs }\end{array}$ & $\begin{array}{l}\text { Presence of new onset hemodialysis, TPN, diabetes mellitus } \\
\text { and broad-spectrum antibiotics predict invasive candidiasis }\end{array}$ \\
\hline Ostrosky-Zeichner [64] & $\begin{array}{l}\text { To identify patients at increased } \\
\text { risk of invasive candidiasis in the } \\
\text { ICU }\end{array}$ & $\begin{array}{l}\text { Mechanical ventilation (days 1-3) } \\
\text { AND } \\
\text { CVC (days 1-3) } \\
\text { AND at least } \mathbf{O N E} \text { of the following } \\
\text { TPN (days 1-3), any dialysis (days 1-3), any major surgery } \\
\text { (days 7-0), pancreatitis (by CT or lipase }>1000 i u \text {, days 7-0), } \\
\text { steroid use (>1dose of prednisone equivalent to 20mg, days 7-0), } \\
\text { other immunosuppressive drug (>1 dose, days } 7-0)\end{array}$ \\
\hline
\end{tabular}

$\mathrm{CVC}=$ Central venous catheter, $\mathrm{LOS}=$ Length of Stay, TPN $=$ Total parenteral nutrition.

\section{Aspergillus}

Aspergillus spp are moulds which are able to cause life-threatening invasive disease in immunocompromised individuals and local disease in immunocompetent persons. The latter can present with a spectra ranging from localised infection of the lungs and sinuses to allergic reactions due to spore inhalation. The species present a worldwide distribution and are found in the environment, plants and decomposing organic matter. Among the hundreds of Aspergillus species few are able to cause disease to humans. The most commonly encountered include $A$. fumigatus followed by $A$. flavus and A. terreus. The epidemiology of aspergillosis in the ICU is difficult to establish due to the inhomogeneity of hospitalised patients, the diagnostic difficulties necessitating a biopsy and the difficulty in discriminating between colonisation and disease [65]. Sometimes autopsy is necessary to prove the diagnosis [66] while a high mortality is reported [67]. Possible sources of Aspergillus in the ICU include improperly cleaned ventilation systems, water systems, or even computer consoles [68]. ICU patients with impaired immunity are prone to develop the invasive form of the disease in lungs and sinuses. Neutropenic patients usually develop the aggressive angioinvasive form while patients under steroid treatment present with a cavitating lesion [65]. Anastomotic regions are the fungus target in patients with lung transplantation [69] while rarer presentations such as endocarditis or osteomyelitis have been described [70,71]. 
The diagnostic approach includes evaluation of possible risk factors, clinical and radiological signs and the implementation of specific laboratory and "high technology" methods.

Persons at greatest risk include patients with haematological malignancies, solid organ transplant recipients, haematopoietic stem cell transplant recipients (HSCT) but also prolonged steroid treatment before ICU admission, chronic obstructive pulmonary disease, severe burns, previous cardiac surgery etc. [65]. Clinical signs and symptoms are not specific e.g. fever not responsive to antibiotics and signs of nosocomial pneumonia. Haematogenous dissemination of Aspergillus to the brain can cause seizures, brain infarctions, intracranial haemorrhage and meningitis.

Radiologic chest radiograph might be negative at the beginning of the disease, or might show nonspecific changes even during the late stages [72] and they include single or multiple small nodules with the "halo sign", a zone of low attenuation with a translucent ground-glass halo around, more frequently appearing in neutropenic patients [73]. Vandewoude et al. recorded nonspecific infiltrates and consolidation as the commonest radiological findings in critically ill patients with Invasive Aspergillosis (IA) [74].

The gold standard of diagnosis of IA is the histopathological identification of Aspergillus in invasive tissue sampling [75]. However, biopsies are rarely performed since critical illness is often associated with coagulation abnormalities, while neutropenia is often accompanied by thrombocytopenia. Moreover the isolation of Aspergillus from cultures of bronchial secretions, broncho alveolar lavage (BAL) or other body fluids or tissues, might represent colonisation rather than infection [76]. However, their positive predictive value is higher in immunosuppressed patients [77]. Focusing on the critically ill the identification of Aspergillus in respiratory samples lies between $10 \%-80 \%$, according to different studies $[78,79]$.

Two non-culture-based diagnostic techniques are available: the detection of galactomannan (GM) and $\beta$-D-glucan, two fungal cell wall components in blood or other body fluids. The first is released in body fluids during Aspergillus growth [72]. It can be detected in serum and BAL, notably before the clinical manifestation of IA [80]. This method leads to the calculation of the galactomannan index (GMI), which is considered to be evidence of IA if it exceeds a certain threshold. However there are false positive results attributed to the concomitant use of $\beta$-lactam antibiotics, to the presence of dietary source of galactomannan (cereals, pasta) or to cross reactivity with other antigens [81]. In nonneutropenic patients the lower sensitivity of the method might be the result of rapid clearing of GM by neutrophils from the circulation [81]. Variable results have been reported in the measurement of GM in BAL and urine and excellent results from cerebrospinal fluid. The reported sensitivity and specificity of GM results in BAL reaches $88 \%$ and $86 \%$ respectively [82]. As for $\beta$-D-glucan, false positive results might be associated to the use of immunoglobulin contaminated with fungal products, the presence of bacterial infections, the administration of several antibiotics and the use of cellulose filters of haemodialysis [83].

An additional method for IA diagnosis is PCR [84]. The sensitivity and specificity of PCR in BAL fluid is $67 \%-100 \%$ and $55 \%-95 \%$, whereas in serum the values are $100 \%$ and $65 \%-92 \%$ respectively $[85,86]$. A possible drawback of PCR diagnostics is the difficulty in discrimination between colonisation and infection [87]. However, according to Li et al., a whole blood quantitative real time PCR (qPCR) targeting to a special gene sequence of the fungus could prove as a clinically reliable technique for diagnosis of IA [88]. Additionally, it has been suggested that qPCR is a 
comparable to GM diagnostic method for IA, and that combining qPCR with GM is a more scientific and sensitive approach to IA diagnostics [89].

The European Organization for Research and Treatment of Cancer/Mycosis Study Group (EORTC/MSG) has incorporated the risk factors, clinical signs and laboratory tests in an attempt to stratify the diagnosis of invasive pulmonary aspergillosis (IPA) into proven, probable, and possible [90]. Histopathologic or cytopathologic examination of a proper specimen is a prerequisite for the proven diagnosis. Probable IPA is confirmed by a combination of clinical and host factors and positive mycological criteria, including cultures or detection of cell wall components. Possible IPA diagnosis is based on the presence of clinical and host features but without positive mycology. However, the aforementioned criteria have been validated in immunosuppressed patients, while in critically ill without classic risk factors this classification has been questioned [74]. Therefore, Blot and colleagues proposed a clinical diagnostic algorithm, deriving from EORTC/MSG in order to diagnose IPA and discriminate colonisation from infection [91]. According to that algorithm, IPA is considered to be probable ("putative") if there are compatible signs, abnormal medical images and either host risk factors or BAL culture positive for Aspergillus. This simple clinical algorithm has been validated in critically ill patients with histopathologically proven aspergillosis, showing specificity $61 \%$ and sensitivity $92 \%$, and might prove to be useful in the IA diagnostics in critically ill patients.

\section{Mucorales}

The class of Zygomycetes is divided in two orders, Entomophtorales and Mucorales. Entomophtorales are rarely implicated in a life-threatening angioinvasive human disease, whereas Mucorales are responsible for mucormycosis, the third commonest invasive fungal infection [92]. Mucorales are traditionally divided in six families: Mucoraceae, Cunninghamellaceae, Saksenacea, Thamnidaceae, Syncephalastraceae and Mortierellaceae. Recently a seventh family, called Absidiaceae, was added. Rhizopus, Mucor, Rhizomucor, Absidia, Apophysomyces, members of the genera of the two families of Mucoraceae-Absidiaceae, are pathogens most commonly implicated in human disease [93].

These organisms are ubiquitous saprophytes in nature rarely infecting organisms with intact immune system. Based on anatomic localization, mucormycosis can be classified in six forms: rhinocerebral, pulmonary, cutaneous, gastrointestinal, disseminated and uncommon presentations [94]. Clinical suspicion arises from the patient's medical history and physical examination. All patients with a chronic infection of the paranasal sinuses, burn or trauma wound infection should have their skin meticulously examined for the presence of either black discoloration or black eschars. A hallmark of the disease is propagating tissue necrosis due to vascular invasion by the fungus, though absence of black discoloration should not exclude the diagnosis. The microbiological laboratory must be notified in order to perform direct mycological examination and culture of a histopathological specimen.

Sporadic mucormycosis is a life - threatening condition, always associated with certain risk factors, mainly neutropenia and prolonged acidosis of either diabetic or renal origin. Mucormycosis in the ICU setting is related more commonly to massive injuries e.g. from motor vehicle accidents, natural disasters $[95,96]$ or complex combat trauma [97]. There has also been one report from a Spanish ICU 
of an outbreak of gastrointestinal mucormycosis due to wooden tongue depressors that had been contaminated by two Rhizopus species [98].

The diagnosis is based on the examination of tissue samples. Stains of fixed tissues with hematoxylin-eosin, Grocott-methanamine-silver (GMS) or periodic acid-Schiff (PAS) are pathognomonic, showing broad nonseptated hyphae, irregularly branched at angles varying from 45-90 [99].Vascular invasion of the lesion and necrosis accompany the infective process. Blood cultures can be obtained but they are seldom positive. Immunochemical tests such as 1,3- $\beta$-glucan or galactomannan are not useful. PCR for the detection of DNA of certain Mucorales species has been recently described, but it cannot be routinely used [100,101]. Table 4 summarizes the techniques available for the diagnosis of Aspergillus and Mucorales spp.

Table 4. Diagnostic approach for invasive Aspergillosis and Mucorales infections in the ICU.

\begin{tabular}{ccc}
\hline Diagnostic method & Aspergillus & Mucorales \\
\hline Histopathology & Definite diagnosis & Definite diagnosis \\
Radiology & No specific findings & No specific findings \\
Blood cultures & Extremely rare & Extremely rare \\
Respiratory samples cultures & Sens: $10 \%-80 \%$ & Sens: $67 \%$, Spec: $100 \%(\mathrm{BAL})$ \\
qPCR blood-BAL & Sens: $67 \%-100 \%$, Spec: $55 \%-95 \%$ & Sens: $40 \%-90 \%$, Spec: $100 \%$ \\
Antigen assays & Galactomannans $(\mathrm{GMI}){ }^{1}>0.5$ & Investigational \\
& Sens: $71 \%$ (BAL $88 \%)$, Spec: $89 \%{ }^{1}$ & \\
& (BAL $86 \%)$ & \\
Algorithms & $1,3-\beta$-glucan & \\
& "Panfungal marker" & \\
& EORTC/MSG criteria ${ }^{2}$ & \\
Sens $=$ Sensitivity, Spec $=$ Specificity, ${ }^{1}$ in patients with haematological cancer or haematopoietic stem cell \\
transplant recipients; ${ }^{2}$ validated in immunosuppressed patients, ${ }^{3}$ in critically ill patients
\end{tabular}

\section{Antifungal Compounds}

Recent decades have seen an impressive progress in the development of our therapeutic antifungal armamentarium. Four classes of antifungal drugs are currently available for the treatment of invasive fungal diseases in critically ill patients. They include: (1) polyenes, (2) azoles, (3) echinocandins and (4) pyrimidine analogues.

\subsection{The Role of Polyenes/Amphotericin B}

For several decades, amphotericin B deoxycholate (AmB) has been the mainstay of treatment for invasive fungal infections. It possesses a broad spectrum of activity against not only most of Candida species- with the exception of $C$ lusitaniae and $C$ guillermondii but also Cryptococcus neoformans and the Mucorales. The antifungal spectrum of the drug also includes filamentous fungi especially Aspergillus spp (with the exception of A. terreus) dimorphic fungi such as Histoplasma, Blastomyces, Coccidioidomyces, Paracoccidiodomyces, and emerging yeasts such as Trichosporon spp and 
Geotrichum spp although Trichosporon strains with high MICs to amphotericin B were detected in some studies [102]. Its efficacy lies upon its fungicidal properties. The drug interacts with the membrane sterol, increases the permeability of the cell membrane and allows leakage of cell components ending to the death of fungus cell $[103,104]$. Despite many years of clinical use, resistance development is unusual except for $C$. glabrata and C. krusei isolates presenting higher minimum inhibitory concentrations (MICs) [105]. On the contrary filamentous fungi exhibit increasing resistance to polyenes [106]. A. fumigatus, the species exhibiting usually susceptibility to amphotericin $\mathrm{B}$, has shown an increase in resistance [107]. The use of conventional AmB is limited due to a narrow therapeutic window and significant adverse effects, especially nephrotoxicity [108] The risk of nephrotoxicity increases significantly with the concomitant use of other nephrotoxic medications. Three lipid formulations of amphotericin B have been developed, namely liposomal amphotericin B (LipAmB), amphotericin B lipid complex and amphotericin B colloidal dispersion, which retain the activity of the parent drug [109,110] and exhibit a better safety profile [111] but have an increased cost compared to AmB. Nevertheless, side effects such as anaemia, thrombocytopenia, nephrotoxicity and hepatotoxicity have been reported with LipAmB, the first two of them presenting in a dose-dependent manner [112]. Moreover it seems that LipAmB is less toxic than the other two [113]. Infusion-related reactions including fever, rigors, chills, myalgia and headaches are also a major problem of AmB use. Slow infusion rates or pretreatment with acetaminophen or hydrocortisone can blunt these reactions which are less frequent or severe when newer lipid formulations are used [109]. In contrast with the 2004 guidelines, the 2009 IDSA guidelines consider AmB and its lipid formulations as alternative agents for the treatment of candidaemia [114] due to the associated nephrotoxicity and not to a diminished therapeutic result [115]. This recommendation has been subject of criticism; in a recent paper, Povoa and Pereira expressed their concern about published data upon which recent guidelines have been based [116]. Dreyfuss and collaborators also claim that there is enough body of evidence to support that if prevention measures are taken (adequate hydration, electrolyte repletion and continuous infusion instead of rapid administration) nephrotoxicity is not a problem while the efficacy remains the same with new treatments [117].

\subsection{Azoles}

Four azole compounds are available for the treatment of invasive fungal diseases: itraconazole, fluconazole, voriconazole and posaconazole.

\subsubsection{Itraconazole}

The older agent of azoles, with a good activity against Aspergillus spp. Once available as oral agent, it is now available in parenteral form as well. The role of itraconazole in critically ill patients with invasive fungal infections (IFI) has not been determined.

\subsubsection{Fluconazole}

Fluconazole is active against most species of Candida with the exception of $C$. glabrata and $C$. krusei but not against Aspergillus or Zygomycetes. Fluconazole acts by inhibiting an enzyme necessary 
for the biosynthesis of cell membrane sterol ergosterol [118] and although it is fungistatic [119,120] it has a proven efficacy for invasive candidiasis in the ICU. The drug is available in both IV and oral formulation, possesses a good safety profile and a low cost. Consequently it is the one of most commonly prescribed antifungal drugs in the ICU. Nevertheless it presents some clinically significant drug interactions such as increased concentrations of cyclosporin, tacrolimus, warfarin, carbamazepin and rifampicine [121]. Especially in the ICU setting important drug - drug interactions concern the usually administered agents fentanyl (anopiate) and midazolam (a sedative benzodiazepine). Because these drugs are extensively metabolized by the isoenzyme CYP3A4/5, co-administration of fluconazole with fentanyl or/and midazolam increases serum levels of those two drugs by competitive inhibition [122] Skrobik et al have shown that levels of fentanyl and midazolam are increased with the co-administration of fluconazole or voriconazole [123]. Elevation of hepatic transaminases and symptoms from the gastrointestinal tract are the commonest adverse effects.

\subsubsection{Voriconazole}

Voriconazole is a second-generation member of azole family. It possesses a broad spectrum of activity covering Candida species including the ones resistant to fluconazole, Cryptococous neoformans, Aspergillus and Fusarium species. Zygomycetes are not susceptible to voriconazole. It is the drug of choice for invasive forms of aspergillosis [124]. It acts by inhibiting the ergosterol synthesis of cell membrane by fungi. It is fungistatic for yeasts but fungicidal for some filamentous fungi [125-128]. Immunomodulatory properties against $A$. fumigatus have also been ascribed to voriconazole [121]. Adverse effects include reversible visual disturbances, confusion, hallucinations, rash and hepatitis. It can be given both orally and intravenously [129,130] but the intravenous form should not be used in patients with creatinine clearance of $<50 \mathrm{~mL} / \mathrm{min}$ or under haemodialysis due to the possible accumulation of cyclodextrin (a solvent vehicle with potential toxic effects) [131] though the studies' results are not uniform [132]. A wide variability in plasma concentrations of the drug make therapeutic drug measurements an important parameter for achieving a therapeutic goal while minimizing adverse effects $[133,134]$. Factors affecting drug levels include age, interactions with other drugs (tacrolimus, sirolimus), liver disease, and genetic polymorphism of the cytochrome CYPZC19. In the ICU setting drugs commonly given and interacting with voriconazole include omeprazole, phenytoin and warfarin. Another important drug interaction includes the co-administration with fentanyl and midazolam, two commonly used drugs in the critically ill patients, the levels of which increase if voriconazole is administered [122,123]. Voriconazole has been successfully used in the ICU setting as salvage treatment in patients with IFIs previously treated with azoles [135].

\subsubsection{Posaconazole}

The newest compound of azoles is active against Candida spp, Aspergillus spp, Cryptococcus and Mucorales. It is available only in oral suspension form (better absorbed when given with a fatty meal) therefore its use in the critically ill is very limited. Posaconazole is given to prevent the fungal infections in neutropenic patients with leukaemia [136]. The compound is also approved as second-line agent for invasive aspergillosis and considered as partially effective for mucormycosis [137]. 


\subsection{Echinocandins}

This is the newest class of antifungal agents developed and they include caspofungin, micafungin and anidulafungin. They possess a limited spectrum of activity covering only Candida and Aspergillus species. Their mode of action is the inhibition of the synthesis of 1,3- $\beta$-glucan, a polysaccharide which maintains the integrity of the cell wall and they are fungicidal in vitro against Candida but fungistatic for Aspergillus [138].

They are given only intravenously in a slow infusion rate in order to avoid the rare infusion - related reactions. Since the active drug is not excreted into the urine their use in candiduria is not suggested. Moreover, the level of echinocandins in special compartments such as cerebrospinal fluid and intraocular compartment remains low. C. parapsilosis is associated with higher MICs and therefore echinocandins are not recommended for candidaemia caused by these species. Their major advantages are the few or negligible interactions with other drugs, especially for micafungin and anidulafungin and their minor adverse effects (abnormal liver function tests, phlebitis, or histamine-like reactions) [139]. Differences between echinocandins are minor [140-142] (see Table 5).

A significant advantage of echinocandins is that being fungicidal they offer much more rapid resolution of symptoms with fewer complications when compared to fluconazole [143]. Due to their favorable therapeutic and safety profile, echinocandin use in the critically ill exhibited a rapid increase and this drug class was established in guidelines as primary treatment option for invasive candidiasis. Increasing use of echinocandins during the last years has raised fears about emergence of resistance but for the present time this phenomenon remains rare [141]. Another concern is the high cost of treatment. Table 6 summarizes the spectrum of antifungal drugs, suggested dose in IC and need of dose adjustment in renal failure.

\subsection{Pyrimidine Analogues}

Flucytosine is the main representative of the class. It is available only as oral formulation in USA but also in intravenous form in other countries and it is mostly used in combination with AmB for special forms of invasive candidiasis (Candida endocarditis, meningitis, or urinary tract candidiasis) or other severe mycosis such as cryptococcosis, aspergillosis and chromoblastomycosis [144].

\section{Future Therapeutic Options}

Newer drugs under investigation include isavuconazole, ravuconazole and albaconazole while a human recombinant monoclonal antibody (Mycograb-Neutec Pharma, Manchester, UK) has been used in combination with AmB showing favorable results $[8,145]$. 
Table 5. Differences on side effects and drug-drug interactions of echinocandins.

\begin{tabular}{lll}
\hline Caspofungin & Micafungin & Anidulafungin \\
\hline $\begin{array}{l}\text { Some interactions with rifampin, phenytoin, } \\
\text { carbamazepine, antiretroviral agents and } \\
\text { dexamethasone [140] }\end{array}$ & $\begin{array}{l}\text { Lacks efficacy and safety data in patients with severe } \\
\text { hepatic impairment. }\end{array}$ & $\begin{array}{l}\text { Does not undergo any degree of hepatic or renal } \\
\text { metabolism }\end{array}$ \\
\hline $\begin{array}{l}\text { Interactions with cyclosporin A (liver function } \\
\text { abnormalities) [141] }\end{array}$ & $\begin{array}{l}\text { Reported formation of liver tumors in rodents rose some } \\
\text { concern about its use ( in humans no similar effects have } \\
\text { been shown) [142] }\end{array}$ & $\begin{array}{l}\text { No dose adjustement is necessary in patients with } \\
\text { hepatic or renal impairment }\end{array}$ \\
\hline
\end{tabular}

Table 6. Spectrum of antifungal drugs, usual dose in invasive infections and dose adjustement in renal failure.

\begin{tabular}{|c|c|c|c|c|c|c|c|c|}
\hline Antifungal drug & C. albicans & C. parapsilosis & C. glabrata & Aspergillus & Mucorales & Cryptococcus & Dose & Dose in Renal failure \\
\hline $\mathrm{AmB}$ & S & S & S & $\mathrm{S} *$ & $\mathrm{~S}$ & S & $0.5-1 \mathrm{mg} / \mathrm{kg} / \mathrm{d}$ & same \\
\hline $\operatorname{lipAmB}$ & $\mathrm{S}$ & $\mathrm{S}$ & $\mathrm{S}$ & $\mathrm{S} *$ & S & $\mathrm{S}$ & $3-5 \mathrm{mg} / \mathrm{kg} / \mathrm{d}$ & same \\
\hline Fluconazole & $\mathrm{S}$ & $\mathrm{S}$ & SDd - R & $\mathrm{R}$ & $\mathrm{R}$ & $\mathrm{S}$ & $\begin{array}{c}800 \mathrm{mg}(12 \mathrm{mg} / \mathrm{kg}) 1 \mathrm{~d} \\
400 \mathrm{mg}(6 \mathrm{mg} / \mathrm{kg})\end{array}$ & Adjustment of the dose \\
\hline Itraconazole & $\mathrm{S}$ & $\mathrm{S}$ & SDd - R & S & $\mathrm{R}$ & Ms & $\begin{array}{c}200 \mathrm{mgIV} / \mathrm{bid} 2 \mathrm{~d} \\
\text { then } 200 \mathrm{mg} / \mathrm{d}\end{array}$ & same \\
\hline Posaconazole & $\mathrm{S}$ & S & SDd - R & S & S & $\mathrm{S}$ & 200 mg qid & Same in mild, moderate \\
\hline Voriconazole & $\mathrm{S}$ & $\mathrm{S}$ & SDd - R & S & $\mathrm{R}$ & $\mathrm{S}$ & $\begin{array}{c}400 \mathrm{mg} / \mathrm{bid} \\
\text { then } 200 \mathrm{mg} / \mathrm{bid}\end{array}$ & $\begin{array}{l}\text { IV not given in } \\
\mathrm{Crcl}<50 \mathrm{~mL} / \mathrm{min}\end{array}$ \\
\hline Flucytosine & S & $\mathrm{S}$ & $\mathrm{S}$ & $\mathrm{R}$ & $\mathrm{R}$ & $\mathrm{S}$ & $\begin{array}{l}50-150 \mathrm{mg} / \mathrm{kg} \\
\text { in } 4 \text { doses }\end{array}$ & Adjustment of the dose \\
\hline Caspofungin & $\mathrm{S}$ & $\mathrm{Rc}$ & $\mathrm{S}$ & $\mathrm{S}$ & $\mathrm{R}$ & $\mathrm{R}$ & $\begin{array}{l}70 \mathrm{mg} / \mathrm{d} \mathrm{l} \mathrm{d} \\
\text { then } 50 \mathrm{mg} / \mathrm{d}\end{array}$ & same \\
\hline Micafungin & $\mathrm{S}$ & $\mathrm{Rc}$ & $\mathrm{S}$ & $\mathrm{S}$ & $\mathrm{R}$ & $\mathrm{R}$ & $100 \mathrm{mg} / \mathrm{d}$ & same \\
\hline Anidulafungin & S & $\mathrm{Rc}$ & $\mathrm{S}$ & $\mathrm{S}$ & $\mathrm{R}$ & $\mathrm{R}$ & $\begin{array}{l}200 \mathrm{mg} / \mathrm{d} \mathrm{l} \mathrm{d} \text {, } \\
\text { then } 100 \mathrm{mg} / \mathrm{d}\end{array}$ & same \\
\hline
\end{tabular}

* Not all Aspergillus spp susceptible to amphotericin B deoxycholate or liposomal amphotericin B. Abbreviations: S: susceptible, R: resistant,Rc: resistance depending on the concentration due to higher MICs of C.parapsilosis to echinocandins, SDd - R: susceptible dependent on dose, AmB: amphotericin B deoxycholate, lip Am B: liposomal amphotericin B, ld: loading dose, bid: twice daily, qid: four times daily, S:susceptible, R: resistant, Ms: modest activity, IV: intravenous form, Crcl : creatinine clearance. 


\section{Management of Candidiasis in the ICU}

\subsection{Documented Invasive Candidiasis}

The time of treatment initiation is a key factor for the favorable outcome of invasive candidiasis. Several studies have shown that delay of initiation of appropriate antimicrobial therapy over 24 or $48 \mathrm{~h}$ has a negative impact on mortality [146-148]. Therefore, if candidaemia is suspected, blood cultures should be taken even in the absence of fever. In the critically ill unstable patient delays in antifungal administration predict death [149]. Consequently treatment has to be started immediately after blood cultures grow yeasts without waiting for the results of identification of Candida species and susceptibility tests [150]. Important considerations in the empirical choice of the right antifungal include the following: knowledge of local resistance patterns; co-morbidities of patient; presence of risk factors favoring the presence of non - albicans species; prior treatment with fluconazole; site of infection; spectrum of activity; known adverse effects; pharmacodynamics /pharmacokinetics; cost of treatment; but the most important factor is the presence of haemodynamic instability [114,150]. According to the current IDSA guidelines the physician can choose between fluconazole, echinocandins, amphotericin B or its lipid formulations and voriconazole (A-I) [114]. Nevertheless, the first two are considered as a preferred choice over the others. In case of (a) haemodynamic instability, (b) previous use of fluconazole or (c) isolation of C. glabrata, echinocandins are preferred to fluconazole. Amphotericin B is characterized as an alternative choice in case of intolerance to the other two, refractory infection, resistant organism or suspicion of infection due to pathogens other than Candida (e.g. cryptococcus). This is a basic difference from the guidelines of 2004 where AmB was a first choice. A step-down from echinocandin to fluconazole is suggested provided there is a clinical improvement and sterilisation of blood cultures. The recent guidelines of the European Society of Clinical Microbiology and Infectious Diseases (ESCMID 2011) [151] endorse the use of echinocandins (grade A) before LipAmB (grade B) and fluconazole (grade C). Echinocandins in patients with severe Candida sepsis are suggested also by Kullberg et al. [152] while the official statements of the American Thoracic Society suggest that in case of haemodynamic instability physicians should choose among AmB or LipAmB, echinocandins, voriconazole or high dose fluconazole [153]. Moreover Canadian guidelines published in 2010 contain specific recommendations about the critically ill [150]. According to these guidelines, fluconazole is preferred in haemodynamically stable patients with no fluconazole exposure during the last 30 days. Echinocandins are an equally accepted alternative. In case of unstable patients (with the exception of $C$. parapsilosis) an echinocandin is preferred. Finally the German speaking Mycological Society and the Paul - Ehrlich Society for Chemotherapy suggest the use of echinocandins or liposomal amphotericin B in critically ill septic patients instead of fluconazole [154].

An important parameter is that every institution should be aware of its resistance rates since in case that resistant Candida is common or at least not negligible, empirical treatment with azoles cannot be recommended. Local and general resistance patterns are often published $[155,156]$ helping physicians in everyday practice particularly in the vulnerable ICU population. Comparison of the guidelines appears in Table 7 and a therapeutic algorithm is suggested in Figure 1. 
Table 7. Suggested treatment of documented candidaemia/invasive candidiasis in nonneutropenic patients according to different guidelines.

\begin{tabular}{|c|c|c|c|}
\hline Society & First line & Alternative I & Alternative II \\
\hline IDSA [114] & $\begin{array}{l}\text { Fluconazole } \\
\text {-stable patient,azole naïve } \\
\text { Echinocandins } \\
\text {-severe sepsis } \\
\text {-recent azole exposure }\end{array}$ & $\begin{array}{l}\text { AmB or lipid formulations of } \\
\text { AmB (intolerance to others or } \\
\text { limited availability) }\end{array}$ & Voriconazole \\
\hline ESCMID [151] & Echinocandins & LipAmB, voriconazole & fluconazole, lcAmB \\
\hline $\begin{array}{l}\text { European Expert } \\
\text { Opinion [152] }\end{array}$ & $\begin{array}{l}\text { Fluconazole } \\
\text { - stable patient } \\
\text { - susceptible isolate } \\
\text { Echinocandins } \\
\text { - severe sepsis } \\
\text { - micafungin last choice }\end{array}$ & $\begin{array}{l}\text { lipidformulations of } \\
\text { amphotericin B }\end{array}$ & \\
\hline $\begin{array}{l}\text { Canadian clinical } \\
\text { practice guidelines for } \\
\text { invasive candidiasis in } \\
\text { adults }[150]\end{array}$ & $\begin{array}{l}\text { Fluconazole } \\
\text {-stable patient,azole naïve } \\
\text {-unstable patient with C.parapsilosis } \\
\text { Echinocandins } \\
\text {-stable or unstable patient } \\
\text {-recent azole exposure } \\
\text {-avoid in C.parapsilosis }\end{array}$ & LipAmB or AmB & \\
\hline $\begin{array}{l}\text { Joint recommendations of } \\
\text { the German speaking } \\
\text { mycological society [154] }\end{array}$ & $\begin{array}{l}\text { Fluconazole } \\
\text {-stable patient } \\
\text {-susceptible isolate } \\
\text { Echinocandins } \\
\text {-critically ill septic patient }\end{array}$ & $\begin{array}{l}\text { LipAmB } \\
\text {-critically ill, septic patients } \\
\text { voriconazole }\end{array}$ & \\
\hline
\end{tabular}

$\mathrm{AmB}=$ amphotericin $\mathrm{B}, \mathrm{Lip} \mathrm{AmB}=$ liposomal amphotericin $\mathrm{B}, \mathrm{lcAmB}=$ lipid complex amphotericin $\mathrm{B}$.

Figure 1. Suggested treatment algorithm for the ICU patient with invasive candidiasis (NAS: non- albicans species, CVC: central venous catheter, AmB: amphotericin B, LipAmB: liposomal amphotericin B).

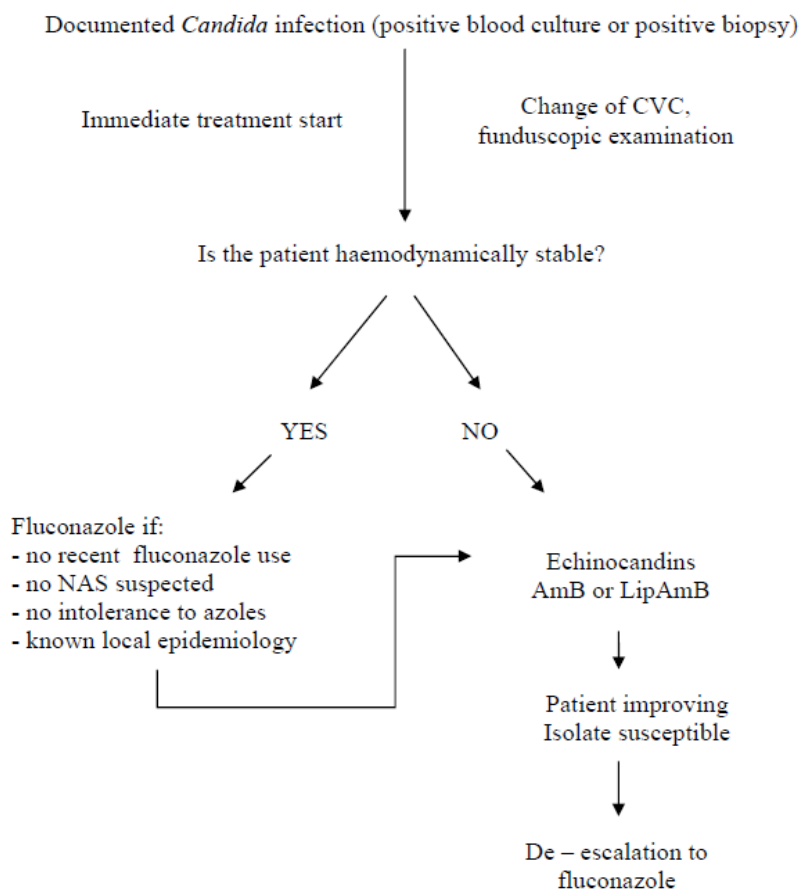


Further important considerations for the practitioner include: (a) the length of therapy (b) the removal of central catheters (c) the fundoscopic examination. Serial blood cultures should be drawn after the start of treatment in order to ascertain blood sterilization. Duration of treatment is defined to 14 days after the last positive blood culture [114,150,154]. In case of persistent fungaemia, a source of local disease e.g. infective endocarditis should be sought and the presence of resistant species must be excluded. The removal of central catheters (as method of source control) is recommended by existing guidelines [114,150,154]. On the contrary some recent studies did not document any outcome improvement after the removal [157,158] while the best time for removal is not well defined, but until further data are available guidelines recommendations should be followed. Furthermore, the ability of biofilm formation in the central catheter by certain Candida spp supports this view. In case of catheterrelated bloodstream infection, an antifungal drug with biofilm action is preferred (AmB or echinocandin). Finally, a fundoscopic examination is of pivotal importance in order to exclude disseminated endocular infection. If a form of localised candidiasis has to be treated, a longer treatment is suggested and the recommended agents are shown in Table 8.

Table 8. Recommended therapy for localised forms of invasive candidiasis according to 2009 IDSA guidelines.

\begin{tabular}{|c|c|}
\hline Infection type & Suggested treatment \\
\hline Pyelonephritis & fluconazole $3-6 \mathrm{mg} / \mathrm{kg} / \mathrm{d}$ (14 days) or AmB $0.3-0.6 \mathrm{mg} / \mathrm{kg} / \mathrm{d}$ for $1-7$ days \\
\hline Urinary fungus ball & $\begin{array}{l}\text { Surgical removal recommended fluconazole } 3-6 \mathrm{mg} / \mathrm{kg} / \mathrm{d} \\
\text { or AmB } 0.5-0.7 \mathrm{mg} / \mathrm{kg} / \mathrm{d}\end{array}$ \\
\hline Candida osteomyelitis & $\begin{array}{l}\text { fluconazole } 6 \mathrm{mg} / \mathrm{kg} / \mathrm{d}(6-12 \mathrm{months}) \text { or LipAmB } 3-5 \mathrm{mg} / \mathrm{kg} / \mathrm{d} \text { (weeks), then } \\
\text { fluconazole for } 6-12 \text { months }\end{array}$ \\
\hline Septic arthritis & $\begin{array}{l}\text { fluconazole } 6 \mathrm{mg} / \mathrm{kg} / \mathrm{d} \text { (6 weeks) or LipAmB 3-5 mg/kg/d (weeks) then } \\
\text { fluconazole }\end{array}$ \\
\hline CNS infection & $\begin{array}{l}\text { LipAmB } 3-5 \mathrm{mg} / \mathrm{kg}( \pm 5 \mathrm{FTC} 25 \mathrm{mg} / \mathrm{kg} / \mathrm{qid}) \text { several weeks, then fluconazole } \\
(6-12 \mathrm{mg} / \mathrm{kg} / \mathrm{d}) \text { daily or fluconazole } 400-800 \mathrm{mg} / \mathrm{d} \text { in LipAmB intolerance }\end{array}$ \\
\hline Endocarditis & $\begin{array}{l}\mathrm{LipAmB} 3-5 \mathrm{mg} / \mathrm{kg}( \pm 5 \mathrm{FTC} 25 \mathrm{mg} / \mathrm{kg} \text { qid }) \text { or } \mathrm{AmB} 0.6-1 \mathrm{mg} / \mathrm{kg} / \mathrm{d}( \pm 5 \mathrm{FTC} \\
25 \mathrm{mg} / \mathrm{kg}) \text { or an echinocandin }\end{array}$ \\
\hline $\begin{array}{l}\text { Suppurative } \\
\text { thrombophlebitis }\end{array}$ & LipAmB $3-5 \mathrm{mg} / \mathrm{kg} / \mathrm{d}$ or fluconazole $400-800 \mathrm{mg} \mathrm{d}$ or an echinocandins \\
\hline Endophthalmitis & $\begin{array}{l}\text { AmB } 0.7-1 \mathrm{mg} / \mathrm{kg} \text { plus } 5 \mathrm{FTC} \text { or fluconazole } 6-12 \mathrm{mg} / \mathrm{kg} / \mathrm{d} \text { or LipAmB } \\
3-5 \mathrm{mg} / \mathrm{kg} / \mathrm{d} \text { or voriconazole } 6 \mathrm{mg} / \mathrm{kg} / 12 \mathrm{~h} \text {, then } 3 \mathrm{mg} / \mathrm{kg} / 12 \mathrm{~h} \text { or echinocandins }\end{array}$ \\
\hline
\end{tabular}

$\mathrm{AmB}=$ Amphotericin $\mathrm{B}, \mathrm{d}=$ daily, $\mathrm{LipAmB}=$ liposomal Amphotericin $\mathrm{B}$, qid=4 times daily, 5FTC = flucytosine.

\subsection{Combination Treatment}

Combination of amphotericin B with flucytosine is recommended in cases of localised infection such as meningitis, osteomyelitis and intra-abdominal infections [159]. 


\subsection{Other Treatment Options}

Because the mortality associated with invasive candidiasis is high while the sensitivity of blood cultures is low other management options exist, including prophylactic, pre-emptive and empirical therapy.

\subsubsection{Prophylaxis}

Prophylaxis is defined as the administration of antifungal agents to high-risk patients without signs or symptoms of infection in order to prevent the development of invasive fungal infection. The agent given systematically for that purpose is mainly fluconazole while recently the use of echinocandins has been successfully tested [160]. Although the benefits of prophylactic therapy in solid organ recipients and haematological neutropenic patients have been well established [114], in critically ill patients results are rather inconclusive because of the difficulty in the definition of high-risk patients in the heterogeneous population hospitalized in the ICU. Routine antifungal prophylaxis of all ICU patients is not recommended [150]. IDSA guidelines suggest the prophylactic use of fluconazole at a dose of $400 \mathrm{mg}$ daily for high-risk ICU adult patients in hospitals with a reported high incidence of invasive candidiasis. Current literature involves several studies, meta-analyses and one Cochrane review [161-171]. These studies have several differences thus making the drawing of a generally applicable conclusion difficult. Most important differences include the heterogeneity in the populations examined - most include surgical ICU populations (SICU) - different doses of fluconazole used, non-similarity in the severity of underlying diseases, different incidence of invasive candidiasis and different end-points. Although some meta-analyses [168,169] concluded that fluconazole prophylaxis offered a reduction of invasive fungal infections and attributable mortality, these results cannot be easily extrapolated due to the aforementioned limitations [172]. It seems that only if the underlying risk is high (almost 10\%) there is a benefit from the prophylaxis [150]. The risk is identified from the presence of risk factors described by Leon, Dupont and Ostrosky-Zeichner [56,60,61]. A reduction in fungal infections without reduction in all-cause mortality was also shown in another meta-analysis which included exclusively patients of SICUs [171]. Accordingly patients with intra-abdominal infections due to recurrent intestinal perforations or anastomotic leakage are rather a population who could benefit from this strategy while this is not the case for severe acute pancreatitis [150]. An important concern about the widespread and imprudent use of fluconazole is evidently the increase in resistance and the shift to non-albicans species. A more judicious approach should include the careful validation of patients at risk taking into consideration local data on rates of different Candida species.

\subsubsection{Pre-Emptive Treatment}

Initiation of antifungal agents in the presence of multiple risk factors constitutes pre-emptive treatment. Prolonged ICU stay, use of broad-spectrum antimicrobials, multi-focal Candida colonisation, presence of gastrointestinal surgery or use of total parenteral nutrition are among the risk factors suggested for use in such cases $[29,172]$. The available literature about the efficacy of preemptive treatment is limited. In a study conducted in a surgical ICU, use of fluconazole as pre-emptive treatment in patients with a high colonisation index (according to Pittet) managed to decrease 
significantly the incidence of ICU-acquired invasive candidiasis without the emergence of fluconazole resistance [173]. In a recent study the monitoring of the serological marker $\beta$-D-glucan was used for identifying ICU patients at highest risk to develop an IFI and for monitoring treatment response [174]. Nevertheless existing evidence is not sufficient and more clinical investigation is required to help physicians decide which patients could benefit from pre-emptive treatment.

\subsubsection{Empirical Treatment}

If antifungal treatment is given to a patient with clinical signs of infection (e.g. persistent fever not responding to antimicrobials) and several risk factors for candidaemia without proof of invasive candidiasis, the term "empirical" may be used. Moreover this term can be applied if antifungal treatment is given to a patient with candidiasis proven by blood culture pending the results of susceptibility tests. In the first case the criteria for therapy initiation are vague in contrast to neutropenic patients and the benefits are not well established. The largest conducted study is the one by Shuster conducted in a SICU. No clear benefit of fluconazole use was proved in that study [175]. IDSA guidelines suggest that candidates for empirical antifungal therapy should be considered the critically ill patients with risk factors for invasive candidiasis and no other known cause of fever. The suggested treatment is similar to that of proven candidiasis. Main concerns about fluconazole overuse in empirical therapy include: development of resistance, therapeutic failure if (suspected) Candida infection is due to NAS and increasing costs [176]. Canadian guidelines suggest that critically ill patients who meet specific criteria based on clinical prediction rules may have a benefit from empirical antifungal therapy [150]. Fluconazole is suggested for stable patients and echinocandins in the presence of haemodynamic instability [150]. Figure 2 includes a suggested algorithm for the use of prophylaxis, preemptive treatment and empirical therapy.

Figure 2. Types of treatment for suspected candidiasis in the critically ill.

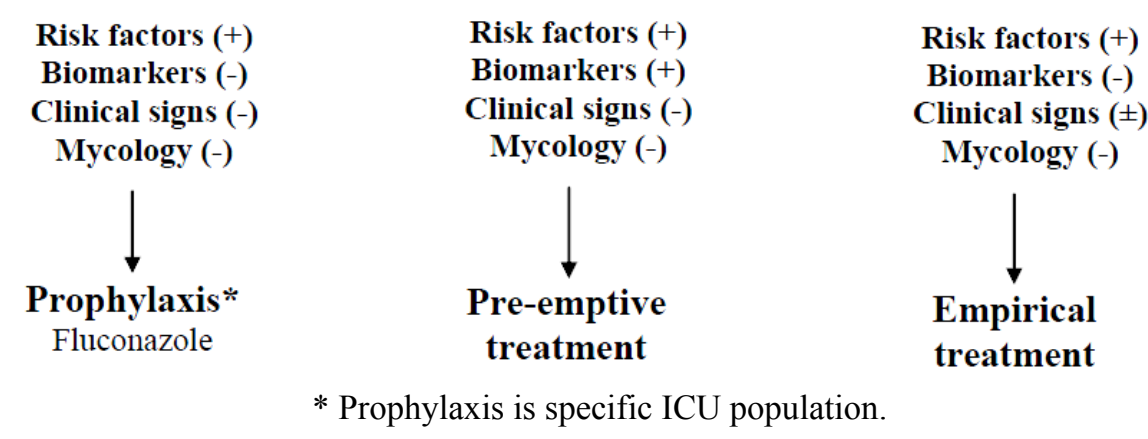

\section{Treatment of Invasive Aspergillosis}

Even a clinical suspicion of IPA should lead to the consideration of initiation of antifungal treatment, since the mortality of the disease remains high. AmB was the antifungal of choice for many years. However, the reported development of resistance among Aspergillus spp and the drug's side effects have limited its use for the treatment of IPA [110]. Lipid-based preparations of AmB (LABA) might be considered as salvage therapy for IPA at a dose of $3-5 \mathrm{mg} / \mathrm{kg} / \mathrm{day}$. High doses of LABA 
$(10 \mathrm{mg} / \mathrm{kg})$ were proven as equally effective with lower doses $(3 \mathrm{mg} / \mathrm{kg} / \mathrm{dose})$ while there was a trend towards more toxicity of the high dose [177].

The treatment of choice for IA is voriconazole [178]. The recommended dose is $6 \mathrm{mg} / \mathrm{kg}$ twice daily on day 1 and then $4 \mathrm{mg} / \mathrm{kg} /$ t.i.d. The therapeutic response to voriconazole might be improved by monitoring therapeutic plasma drug levels. Another triazole, posaconazole, might be effective in IPA as salvage therapy or as prophylactic therapy in neutropenic patients. Itraconazole is an alternative option for IA refractory to AmB. Adequate absorption of the oral form should be documented by measurement of serum levels.

Other alternative drugs for the refractory cases of IPA are the echinocandins. Caspofungin has shown favorable results in patients with IA refractory to first line antifungals [179]. Micafungin and anidulafungin are not approved for IA treatment despite their activity against Aspergillus spp [178]. Combination of azoles and echinocandins might be used in refractory cases of IA [163]. The combination of voriconazole plus caspofungin compared to voriconazole led to survival advantage according to a retrospective analysis of IPA treatment [180,181]. Additionally in critically ill the combination of echinocandin with a lipid formulation of AmB might prove to be effective [181]. On the contrary the combination of voriconazole with $\mathrm{AmB}$ might lead to an antagonistic effect. According to IDSA guidelines combination therapy might be used in terms of salvage therapy and randomized controlled studies are indicated for further justification [178].

The duration of IPA treatment might last from several months to more than one year and should be tailored to patients' response $[178,182]$. Clinical and radiological response is necessary for cessation of treatment whereas improvement of immunosuppression and sterilisation of cultures might play an important role too. Intrinsic or secondary antifungal resistance might be related to treatment failure. A.terreus shows primary resistance to $\mathrm{AmB}$ while similar susceptibility results have been demonstrated for several species of the Fumigati group [179,180]. Multiple triazole resistance has increasingly been detected in A. fumigatus possibly due to genotypically determined resistance mechanism. Cross-resistance to triazole has also been reported. According to IDSA guidelines, itraconazole should not be used for treatment of IPA refractory to voriconazole because of the possibility of cross-resistance and the subsequent toxicity [178].

A reduction of the degree of immunosuppression by immunomodulatory therapy is a possible adjunctive factor to successful therapy of IPA. According to IDSA guidelines neutropenic patients with IPA might benefit from the administration of granulocyte colony-stimulating factor (G-CSF) or granulocyte-macrophage colony-stimulating factor (GM-CSF) [180]. There are also limited clinical data regarding the benefit of adding interferon- $\gamma$ [183]. Granulocyte transfusion might be another adjunct to antifungals in patients with IPA but randomized control studies are lacking [168]. Finally the decrease of the dosage of systemic corticosteroids and immunosuppressive agents might contribute to a successful treatment [182].

Additional measures for prevention of IPA are the use of high - efficiency particulate air filtration (HEPA) and the avoidance of hospitalisation in areas with construction procedures [184]. Regarding chemoprophylaxis itraconazole or posaconazole can be used in patients with haematological malignancies and relative clinical trials are running [185]. 


\section{Treatment Of Mucorales Infection}

The treatment of Mucorales spp. requires several simultaneous approaches: aggressive (sometimes disfiguring) surgical intervention, antifungal drug therapy and management of all underlying medical conditions that might predispose the patient to the disease. On diagnosis LipAmB should be started at a dose $5-10 \mathrm{mg} / \mathrm{kg}$ once daily. The maximal dose is indicated for mucormycosis with intracerebral extension. Posaconazole, a new triazole antifungal agent, is currently considered as a second-line drug for the treatment of mucormycosis at a dose of $400 \mathrm{mg}$ twice daily. Its use is recommended in combination with LipAmB or as sequential long-term therapy. Granulocyte-macrophage colonystimulating factor (GM-CSF) and hyperbaric oxygen have been used adjunctively in neutropenic patients offering doubtful results [186].

\section{Conclusions}

Invasive fungal infections in the critical care setting often constitute a challenging diagnostic and therapeutic problem. Clinical awareness, knowledge of local epidemiology and pharmaceutical considerations are factors of paramount importance for an early diagnosis and treatment of these potentially lethal infectious diseases.

\section{Acknowledgments}

We would like to thank ASTELLAS Greece for their financial support in the publication of the manuscript.

\section{Author Contributions}

George Dimopoulos was responsible for the subject of the review and did the final editing of the manuscript. Elisabeth Paramythiotou wrote the review except for the Candida diagnosis (Aikaterini Flevari), the Mucorales (Aikaterini Flevari) and Aspergillus (Frantzeska Frantzeskaki) and was also responsible for the revision and the proofs. Apostolos Armaganidis was also responsible for the editing.

\section{Conflicts of Interest}

The authors declare no conflict of interest.

\section{References}

1. Blot, S.; Dimopoulos, G.; Rello, J.; Vogelaers, D. Is Candida really a threat in the ICU? Curr. Opin. Crit. Care 2008, 14, 600-604.

2. Darouiche, R.O. Candida in the ICU. Clin. Chest Med. 2009, 30, 287-293.

3. Vincent, J.L.; Rello, J.; Marshall, J.; Silva, E.; Anzueto, A.; Martin, C.D.; Moreno, R.; Lipman, J.; Gomersall, C.; Sakr, Y. Konrad ReinhartInternational study of the prevalence and outcomes of infection in intensive care units. JAMA 2009, 21, 2323-2329. 
4. Falagas, M.E.; Apostolou, K.E.; Pappas, V.D. Attributable mortality of candidemia: A systematic review of matched cohort and case-control studies. Eur. J. Clin. Microbiol. Infect. Dis. 2006, 25, 419-425.

5. Gagne, J.J.; Goldfarb, N.I. Candidaemia in the in-patient setting. Expert Opin. Pharmacother. 2007, 8, 1643-1650.

6. Fridkin, K.; Jarvis, R. Epidemiology of nosocomial fungal infections. Clin. Microbiol. Rev. 1996, 9 , 499-511.

7. Pfaller, M.; Diekema, D.J. Epidemiology of invasive candidiasis: A persistent public health problem. Clin. Microbiol. Rev. 2007, 20, 133-163.

8. Tragiannidis, A.; Tsoulas, C.; Kerl, K.; Groll, A.H. Invasive candidiasis: Update on current pharmacotherapy options and future perspectives. Expert Opin. Pharmacother. 2013, 14, 1515-1528.

9. Asmundsdottir, L.R.; Erlendsdottir, H.; Haraldsson, G.; Guo, H.; Xu, J.; Gottfredsson, M. Molecular epidemiology of candidemia: Evidence of clusters of smoldering nosocomial infections. Clin. Infect. Dis. 2008, 47, e17-e24.

10. Concia, E.; Azzini, A.M.; Conti, M. Epidemiology, incidence and risk factors for invasive candidiasis in high-risk patients. Drugs 2009, 69, 5-14.

11. Wisplinghoff, H.; Bischoff, T.; Tallent, S.M.; Seifert, H.; Wenzel, RP.; Edmond, M.B. Nosocomial bloodstream infections in US hospitals: Analysis of 24,179 cases from a prospective nationwide surveillance study. Clin. Infect. Dis. 2004, 39, 309-317.

12. Almirante, B.; Rodriguez, D.; Park, B.J.; Cuenca-Estrella, M.; Planes, A.M.; Almela, M.; Mensa, J.; Sanchez, F.; Ayats, J.; Gimenezet, M.; et al. Epidemiology and predictors of mortality in cases of Candida bloodstream infection: Results from population-based surveillance, Barcelona, Spain, from 2002 to 2003. J. Clin. Microbiol. 2005, 43, 1829-1835.

13. Asmundsdottir, L.R.; Erlendsdottir, H.; Gottfredsson, M. Nationwide study of candidemia, antifungal use and antifungal drug resistance in Iceland, 2000 to 2011. J. Clin. Microbiol. 2013, 51, 841-848.

14. Tortorano, A.M.; Peman, J.; Bernhardt, H.; Klingspor, L.; Kibbler, C.C.; Faure, O.; Biraghi, E.; Canton, E.; Zimmermann, K.; Seaton, S.; et al. Epidemiology of candidaemia in Europe: Results of 28-month European Confederation of Medical Mycology (ECMM) hospital-based surveillance study. Eur. J. Clin. Microbiol. Infect. Dis. 2004, 23, 317-322.

15. Prowle, J.R.; Echeverri, J.E.; Ligabo, E.V.; Sherry, N.; Taori, G.C.; Crozier, T.M.; Biraghi, E.; Canton, E.; Zimmermann, K.; Seaton, S.; et al. Acquired bloodstream infection in the intensive care unit: Incidence and attributable mortality. Crit. Care 2011, 15, R100.

16. Meyer, E.; Geffers, C.; Gastmeier, P.; Schwab, F. No increase in primary nosocomial candidemia in 682 German intensive care units during 2006 to 2011. Euro. Surveill. 2013, 18, doi:10.1007/s15010-013-0531-y.

17. Montagna, M.T.; Caggiano, G.; Lovero, G.; de Giglio, O.; Coretti, C.; Cuna, T.; Iatta, R.; Giglio, M.; Dalfino, L.; Bruno, F.; et al. Epidemiology of invasive fungal infections in the intensive care unit: Results of a multicenter Italian survey (AURORA Project). Infection 2013, 41, 645-653. 
18. Quenot, J.P.; Binquet, C.; Kara, F.; Martinet, O.; Ganster, F.; Navellou, J.C.; Castelain, V.; Barraud, D.; Cousson, J.; Louis, G.; et al. The epidemiology of septic shock in French intensive care units: The prospective multicenter cohort EPISS study. Crit. Care 2013, 17, R65.

19. Tabah, A.; Koulenti, D.; Laupland, K.; Misset, B.; Valles, J.; Bruzzi de Carvalho, F.; Paiva, J.A.; Cakar, N.; Ma, X.; Eggimann, P.; et al. Characteristics and determinants of outcome of hospital-acquired bloodstream infections in intensive care units: The EUROBACT International Cohort Study. Intensiv. Care Med. 2012, 38, 1930-1945.

20. Alangaden, G.J. Nosocomial fungal infections: Epidemiology, infection control, and prevention. Infect. Dis. Clin. North. Am. 2011, 1, 201-225.

21. Mikulska, M.; Calandra, T.; Sanguinetti, M.; Poulain, D.; Viscoli, C. The use of mannan antigen and anti-mannan antibodies in the diagnosis of invasive candidiasis: Recommendations from the Third European Conference on Infections in Leukemia. Crit. Care 2010, 14, R222.

22. Zaoutis, T.E.; Argon, J.; Chu, J.; Berlin, J.A.; Walsh, T.J.; Feudtner, C. The epidemiology and attributable outcomes of candidemia in adults and children hospitalized in the United States: A propensity analysis. Clin. Infect. Dis. 2005, 41, 1232-1239.

23. Falagas, M.E.; Roussos, N.; Vardakas, K.Z. Relative frequency of albicans and the various non-albicans Candida spp among candidemia isolates from inpatients in various parts of the world: A systematic review. Int. J. Infect. Dis. 2010, 14, e954-e966.

24. Bloos, F.; Bayer, O.; Sachse, S.; Straube, E.; Reinhart, K.; Kortgen, A. Attributable costs of patients with candidemia and implications of polymerase chain reaction-based pathogen detection on antifungal therapy in patients with sepsis. J. Crit. Care 2013, 28, 2-8.

25. Hajjeh, R.A.; Sofair, A.N.; Harrison, L.H.; Lyon, G.M.; Arthington-Skaggs, B.A.; Mirza, S.A.; Phelan, M.; Morgan, J.; Lee-Yang, W.; Ciblak, M.A.; et al. Incidence of bloodstream infections due to Candida species and in vitro susceptibilities of isolates collected from 1998 to 2000 in a population-based active surveillance program. J. Clin. Microbiol. 2004, 42, 1519-1527.

26. Horn, D.L.; Neofytos, D.; Anaissie, E.J.; Fishman, J.A.; Steinbach, W.J.; Olyaei, A.J.; Marr, K.A.; Pfaller, M.A.; Chang, C.-H.; Webster, K.M. Epidemiology and outcomes of candidemia in 2019 patients: Data from the prospective antifungal therapy alliance registry. Clin. Infect. Dis. 2009, 48, 1695-1703.

27. Pfaller, M.A.; Diekema, D.J.; Rinaldi, M.G.; Barnes, R.; Hu, B.; Veselov, A.V.; Tiraboschi, N.; Nagy, E.; Gibbs, D.L. Results from the ARTEMIS DISK Global Antifungal Surveillance Study: A 6.5-year analysis of susceptibilities of Candida and other yeast species to fluconazole and voriconazole by standardized disk diffusion testing. J. Clin. Microbiol. 2005, 43, 5848-5859.

28. Shorr, A.F.; Lazarus, D.R.; Sherner, J.H.; Jackson, W.L.; Morrel, M.; Fraser, V.J.; Kollef, M.H.; Do clinical features allow for accurate prediction of fungal pathogenesis in bloodstream infections? Potential implications of the increasing prevalence of non-albicans candidemia. Crit. Care Med. 2007, 35, 1077-1083.

29. Bassetti, M.; Righi, E.; Costa, A.; Fasce, R.; Molinari, M.P.; Rosso, R.; Pallavicini, F.B.; Viscoli, C. Epidemiological trends in nosocomial candidemia in intensive care. BMC Infect. Dis. 2006, 6, 21.

30. Leroy, O.; Gangneux, J.P.; Montravers, P.; Mira, J.P.; Gouin, F.; Sollet, J.P.; Carlet, J.; Lortholary, O. Epidemiology, management, and risk factors for death of invasive Candida 
infections in critical care: A multicenter, prospective, observational study in France (2005-2006). Crit. Care Med. 2009, 37, 1612-1618.

31. Chow, J.K.; Golan, Y.; Ruthazer, R.; Karchmer, A.W.; Carmeli, Y.; Lichtenberg, D.A.; Chawla, V.; Young, J.A.; Hadley, S. Risk factors for albicans and non-albicans candidemia in the intensive care unit. Crit. Care Med. 2008, 36, 1993-1998.

32. Dimopoulos, G.; Ntziora, F.; Rachiotis, G.; Armaganidis, A.; Falagas, M.E. Candida albicans versus non-albicans intensive care unit-acquired bloodstream infections: Differences in risk factors and outcome. Anesth. Analg. 2008, 106, 523-529.

33. Marr, K.A.; Seidel, K.; White, T.C.; Bowden, R.A. Candidemia in allogeneic blood and marrow transplant recipients: Evolution of risk factors after the adoption of prophylactic fluconazole. J. Infect. Dis. 2000, 181, 309-316.

34. Playford, E.G.; Marriott, D.; Nguyen, Q.; Chen, S.; Ellis, D.; Slavin, M.; Sorrell, T.C. Candidemia in nonneutropenic critically ill patients: Risk factors for non-albicans Candida spp. Crit. Care Med. 2008, 36, 2034-2039.

35. Abi-Said, D.; Anaissie, E.; Uzun, O.; Raad, I.; Pinzcowski, H.; Vartivarian, S. The epidemiology of hematogenous candidiasis caused by different Candida species. Clin. Infect. Dis. 1997, 24, $1122-1128$.

36. Nguyen, M.H.; Wissel, M.C.; Shields, R.K.; Salomoni, M.A.; Hao, B.; Press, E.G.; Shields, R.M.; Cheng, S.; Mitsani, D.; Vadnerkar, A.; et al. Performance of Candida real-time polymerase chain reaction, beta-D-glucan assay, and blood cultures in the diagnosis of invasive candidiasis. Clin. Infect. Dis. 2012, 54, 1240-1248.

37. Guery, B.P.; Arendrup, M.C.; Auzinger, G.; Azoulay, E.; Borges, S.M.; Johnson, E.M.; Müller, E.; Putensen, C.; Rotstein, C.; Sganga, G.; et al. Management of invasive candidiasis and candidemia in adult non-neutropenic intensive care unit patients: Part I. Epidemiology and diagnosis. Intensiv. Care Med. 2009, 35, 55-62.

38. Ahmad, S.; Khan, Z. Invasive candidiasis: A review of nonculture-based laboratory diagnostic methods. Indian J. Med. Microbiol. 2012, 30, 264-269.

39. Sendid, B.; Poirot, J.L.; Tabouret, M.; Bonnin, A.; Caillot, D.; Camus, D.; Poulain, D. Combined detection of mannanaemia and antimannan antibodies as a strategy for the diagnosis of systemic infection caused by pathogenic Candida species. J. Med. Microbiol. 2002, 51, 433-442.

40. Koo, S.; Bryar, J.M.; Page, J.H.; Baden, L.R.; Marty, F.M. Diagnostic performance of the (1-->3)-beta-D-glucan assay for invasive fungal disease. Clin. Infect. Dis. 2009, 49, 1650-1659.

41. Ostrosky-Zeichner, L.; Alexander, B.D.; Kett, D.H.; Vazquez, J.; Pappas, P.G.; Saeki, F.; Ketchum, P.A.; Wingard, J.; Schiff, R.; Tamura, H.; et al. Multicenter clinical evaluation of the (1-->3) beta-D-glucan assay as an aid to diagnosis of fungal infections in humans. Clin. Infect. Dis. 2005, 41, 654-659.

42. Sendid, B.; Tabouret, M.; Poirot, J.L.; Mathieu, D.; Fruit, J.; Poulain, D. New enzyme immunoassays for sensitive detection of circulating Candida albicans mannan and a.ntimannan antibodies: Useful combined test for diagnosis of systemic candidiasis. J. Clin. Microbiol. 1999, $37,1510-1517$. 
43. Prella, M.; Bille, J.; Pugnale, M.; Duvoisin, B.; Cavassini, M.; Calandra, T.; Marchetti, O. Early diagnosis of invasive candidiasis with mannan antigenemia and antimannan antibodies. Diagn. Microbiol. Infect. Dis. 2005, 51, 95-101.

44. Mokaddas, E.; Khan, Z.U.; Ahmad, S.; Nampoory, M.R.; Burhamah, M. Value of (1-3)-beta-Dglucan, Candida mannan and Candida DNA detection in the diagnosis of candidaemia. Clin. Infect. Dis. 2011, 17, 1549-1553.

45. Peman, J.; Zaragoza, R. Current diagnostic approaches to invasive candidiasis in critical care settings. Mycoses 2010, 53, 424-433.

46. Posteraro, B.; De Pascale, G.; Tumbarello, M.; Torelli, R.; Pennisi, MA.; Bello, G.; Maviglia, R.; Fadda, G.; Sanguinetti, M.; Antonelli, M. Early diagnosis of candidemia in intensive care unit patients with sepsis: A prospective comparison of (1-->3)-beta-D-glucan assay, Candida score, and colonisation index. Crit. Care 2011, 15, R249.

47. Quindos, G.; Moragues, M.D.; Ponton, J. Is there a role for antibody testing in the diagnosis of invasive candidiasis? Rev. Iberoam. Micol. 2004, 21, 10-14.

48. McMullan, R.; Metwally, L.; Coyle, P.V.; Hedderwick, S.; McCloskey, B.; O’Neill, H.J.; Patterson, C.C.; Thompson, G.; Webb, C.H.; Hay, R.J. A prospective clinical trial of a real-time polymerase chain reaction assay for the diagnosis of candidemia in nonneutropenic, critically ill adults. Clin. Infect. Dis. 2008, 46, 890-896.

49. Ahmad, S.; Khan, Z.; Mustafa, A.S.; Khan, Z.U. Seminested PCR for diagnosis of candidemia: Comparison with culture, antigen detection, and biochemical methods for species identification. J. Clin. Microbiol. 2002, 40, 2483-2489.

50. Marklein, G.; Josten, M.; Klanke, U.; Müller, E.; Horré, R.; Maier, T.; Kostrzewa, M.; Bierbaum, G.; Hoerauf, A.; Sahl, H.-G. Matrix-assisted laser desorption inozation-time of flight mass spectrometry for fast and reliable identification of clinical yeast isolates. J. Clin. Microbiol. 2009, 47, 2912-2917.

51. Shepard, J.R.; Addison, R.M.; Alexander, B.D.; Della-Latta, P.; Gherna, M.; Haase, G.; Hall, G.; Johnson, J.K.; Merz, W.G.; Peltroche-Llacsahuanga, H.; et al. Multicenter evaluation of the Candida albicans/Candida glabrata peptide nucleic acid fluorescent in situ hybridization method for simultaneous dual-color identification of C.albicans and C.glabrata directly from blood cultures bottles. J. Clin. Microbiol. 2009, 46, 50-55.

52. Calderaro, A.; Martinelli, M.; Motta, F.; Larini, S.; Arcangeletti, M.C.; Medici, M.C.; Chezzi, C.; Conto, F. Comparison of peptide nucleic acid fluorescence in situ hybridization (PNA FISH) assays with culture based matrix-assisted laser desorption/ionization-time of flight (MALDI-TOF) Mass Spectrometry for the identification of bacteria and yeasts from blood cultures and cerebrospinal fluid cultures. Clin. Microbiol. Infect. 2013, doi:10.1111/1469-0691.12490.

53. Luzzati, R.; Cavinato, S.; Giangreco, M.; Granà, G.; Centonze, S.; Deiana, M.L.; Biolo, G.; Barbone, F. Peripheral and total parenteral nutrition as the strongest risk factors for nosocomial candidemia in elderly patients: A matched case-control study. Mycoses 2013, 56, 664-671.

54. Muskett, H.; Shahin, J.; Eyres, G.; Harvey, S.; Rowan, K.; Harrison, D. Risk factors for invasive fungal disease in critically ill adult patients: A systematic review. Crit. Care 2011, 15, R287. 
55. Hoffmann-Santos, H.D.; Paula, C.R.; Yamamoto, A.C.; Tadano, T.; Hahn, R.C. Six-year trend analysis of nosocomial candidemia and risk factors in two intensive care hospitals in Mato Grosso, Midwest Region of Brazil. Mycopathologia 2013, 176, 409-415.

56. Leon, C.; Ruiz-Santana, S.; Saavedra, P.; Castro, C.; Ubeda, A.; Loza, A.; Hernández-Viera, M.A. Usefulness of the "Candida score" for discriminating between Candida colonisation and invasive candidiasis in non-neutropenic critically ill patients: A prospective multicenter study. Crit. Care Med. 2009, 37, 1624-1633.

57. Blumberg, H.M.; Jarvis, W.R.; Soucie, J.M.; Edwards, J.E.; Patterson, J.E.; Pfaller, M.A.; Rangel-Frausto, M.S.; Rinaldi, M.G.; Saiman, L.; Wiblin, R.T.; et al. Risk factors for candidal bloodstream infections in surgical intensive care unit patients: The NEMIS prospective multicenter study. The National Epidemiology of Mycosis Survey. Clin. Infect. Dis. 2001, 33, 177-186.

58. Agvald-Ohman, C.; Klingspor, L.; Hjelmqvist, H.; Edlund, C. Invasive candidiasis in long-term patients at a multidisciplinary intensive care unit: Candida colonisation index, risk factors, treatment and outcome. Scand. J. Infect. Dis. 2008, 40, 145-153.

59. Pittet, D.; Monod, M.; Suter, P.M.; Frenk, E.; Auckenthaler, R. Candida colonisation and subsequent infections in critically ill surgical patients. Ann. Surgery 1994, 220, 751-758.

60. Dupont, H.; Bourichon, A.; Paugam-Burtz, C.; Mantz, J.; Desmonts, J.M. Can yeast isolation in peritoneal fluid be predicted in intensive care unit patients with peritonitis? Crit. Care Med. 2003, 31, 752-757.

61. Ostrosky-Zeichner, L.; Sable, C.; Sobel, J.; Alexander, B.D.; Donowitz, G.; Kan, V.; Kauffman, C.A.; Kett, D.; Larsen, R.A.; Morrison, V.; et al. Multicenter retrospective development and validation of a clinical prediction rule for nosocomial invasive candidiasis in the intensive care setting. Eur. J. Clin. Microbiol. Infect. Dis. 2007, 26, 271-276.

62. Hermsen, E.D.; Zapapas, M.K.; Maiefski, M.; Rupp, M.E.; Freifeld, A.G.; Kalil, A.C. Validation and comparison of clinical prediction rules for invasive candidiasis in intensive care unit patients: A matched case-control study. Crit. Care 2011, 15, R198.

63. Paphitou, N.I.; Ostrosky-Zeichner, L.; Rex, J.H. Rules for identifying patients at increased risk for candidal infections in the surgical intensive care unit: Approach to developing practical criteria for systematic use in antifungal prophylaxis trials. Med. Mycol. 2005, 43, 235-243.

64. Ostrosky-Zeichner, L. Clinical prediction rules for invasive candidiasis in the ICU: Ready for prime time? Crit. Care 2011, 15, 1-2.

65. Meersseman, W.; Lagrou, K.; Maertens, J.; van Wijngaerden, E. Invasive aspergillosis in the intensive care unit. Clin. Infect. Dis. 2007, 45, 205-216.

66. Dimopoulos, G.; Piagnerelli, M.; Berre, J.; Eddafali, B.; Salmon, I.; Vincent, J.L. Disseminated aspergillosis in intensive care unit patients: An autopsy study. J. Chemother. 2003, 15, 71-75.

67. Meersseman, W.; Vandecasteele, S.J.; Wilmer, A.; Verbeken, E.; Peetermans, W.E.; van Wijngaerden, E. Invasive aspergillosis in critically ill patients without malignancy. Am. J. Resp. Crit. Care Med. 2004, 170, 621-625.

68. Warris, A.; Verweij, P.E. Clinical implications of environmental sources for Aspergillus. Med. Mycol. 2005, 43, S59-S65. 
69. Mehrad, B.; Paciocco, G.; Martinez, F.J.; Ojo, T.C.; Iannettoni, M.D.; Lynch, J.P. Spectrum of Aspergillus infection in lung transplant recipients: Case series and review of the literature. Chest 2001, 119, 169-175.

70. Pasqualotto, A.C.; Denning, D.W. Post-operative aspergillosis. Clin. Microbiol. Infect. 2006, 12, 1060-1076.

71. Dimopoulos, G.; Tsangaris, I.; Poulakou, G.; Panayiotides, J.; Tsaknis, G.; Orfanos, S.; Armaganides, A. Post-operative Aspergillus mediastinitis in a man who was immunocompetent: A case report. J. Med. Case Rep. 2010, 4, 312.

72. Barnes, P.D.; Marr, K.A. Risks, diagnosis and outcomes of invasive fungal infections in haematopoietic stem cell transplant recipients. Br. J. Haematol. 2007, 139, 519-531.

73. Cornillet, A.; Camus, C.; Nimubona, S.; Gandemer, V.;Tattevin, P.; Belleguic, C.; Chevrier, S.; Meunier, C.; Lebert, C.; Aupée, M.; et al. Comparison of epidemiological, clinical, and biological features of invasive aspergillosis in neutropenic and nonneutropenic patients: A 6-year survey. Clin. Infect. Dis. 2006, 43, 577-584.

74. Vandewoude, K.H.; Blot, S.I.; Depuydt, P.; Benoit, D.; Temmerman, W.; Colardyn, F.; Vogelaers, D. Clinical relevance of Aspergillus isolation from respiratory tract samples in critically ill patients. Crit. Care 2006, 10, R31.

75. Ruhnke, M.; Bohme, A.; Buchheidt, D.; Cornely, O.; Einsele, H.; Enzensberger, R.; Hebart, H.; Heinz, W.; Junghanss, C.; Karthaus, M.; et al. Diagnosis of invasive fungal infections in hematology and oncology--guidelines of the Infectious Diseases Working Party (AGIHO) of the German Society of Hematology and Oncology (DGHO). Ann. Haematol. 2003, 82, S141-S148.

76. Perfect, J.R.; Cox, G.M.; Lee, J.Y.; Kauffman, C.A.; de Repentigny, L.; Chapman, S.W.; Morrison, V.A.; Pappas, P.; Hiemenz, J.W.; Stevens, D.A. The impact of culture isolation of Aspergillus. species: A hospital-based survey of aspergillosis. Clin. Infect. Dis. 2001, 33, 1824-1833.

77. Horvath, J.A.; Dummer, S. The use of respiratory-tract cultures in the diagnosis of invasive pulmonary aspergillosis. Am. J. Med. 1996, 100, 171-178.

78. Soubani, A.O.; Chandrasekar, P.H. The clinical spectrum of pulmonary aspergillosis. Chest 2002, 121, 1988-1999.

79. Fukuda, T.; Boeckh, M.; Carter, R.A.; Sandmaier, B.M.; Maris, M.B.; Maloney, D.G.; Martin, P.J.; Storb, R.F.; Marr, K.A. Risks and outcomes of invasive fungal infections in recipients of allogeneic hematopoietic stem cell transplants after nonmyeloablative conditioning. Blood 2003, 102, 827-833.

80. Locatelli, F.; Barbui, A.; Limerutti, G.; Serra, R.; Libertucci, D.; Falda, M. Usefulness of sequential Aspergillus galactomannan antigen detection combined with early radiologic evaluation for diagnosis of invasive pulmonary aspergillosis in patients undergoing allogeneic stem cell transplantation. Transplant. Proc. 2006, 38, 1610-1613.

81. Herbrecht, R.; Letscher-Bru, V.; Oprea, C.; Lioure, B.; Waller, J.; Campos, F.; Villard, O.; Liu, K.-L.; Natarajan-Amé, S.; Lutz, P.; et al. Aspergillus galactomannan detection in the diagnosis of invasive aspergillosis in cancer patients. J. Clin. Oncol. 2002, 20, 1898-1906.

82. Klont, R.R.; Mennink-Kersten, M.A.; Verweij, P.E. Utility of Aspergillus antigen detection in specimens other than serum specimens. Clin. Infect. Dis. 2004, 39, 1467-1474. 
83. Digby, J.; Kalbfleisch, J.; Glenn, A.; Larsen, A.; Browder, W.; Williams, D. Serum glucan levels are not specific for presence of fungal infections in intensive care unit patients. Clin. Diagn. Lab. Immunol. 2003, 10, 882-885.

84. Wengenack, N.L.; Binnicker, M.J. Fungal molecular diagnostics. Clin. Chest Med. 2009, 30, 391-408.

85. Hizel, K.; Kokturk, N.; Kalkanci, A.; Ozturk, C.; Kustimur, S.; Tufan, M. Polymerase chain reaction in the diagnosis of invasive aspergillosis. Mycoses 2004, 47, 338-342.

86. Halliday, C.; Hoile, R.; Sorrell, T.; James, G.; Yadav, S.; Shaw, P.; Bleakley, M.; Bradstock, K.; Chen, S. Role of prospective screening of blood for invasive aspergillosis by polymerase chain reaction in febrile neutropenic recipients of haematopoietic stem cell transplants and patients with acute leukaemia. Br. J. Haematol. 2006, 132, 478-486.

87. Hsu, J.L.; Ruoss, S.J.; Bower, N.D.; Lin, M.; Holodniy, M.; Stevens, D.A. Diagnosing invasive fungal disease in critically ill patients. Crit. Rev. Microbiol. 2011, 37, 277-312.

88. Li, Y.; Gao, L.; Ding, Y.; Xu, Y.; Zhou, M.; Huang, W.; Jing, Y.; Li, H.; Wang, L.; Yu, L. Establishment and application of real-time quantitative PCR for diagnosing invasive aspergillosis via the blood in hematological patients: Targeting a specific sequence of Aspergillus 28S-ITS2. BMC Infect. Dis.2013, 13, 255.

89. Springer, J.; Morton, C.O.; Perry, M.; Heinz, W.J.; Paholcsek, M.; Alzheimer, M.; Rogersb, T.R.; Barnesd, R.A.; Einselea, H.; Loeffler, J.; et al. Multicenter comparison of serum and whole-blood specimens for detection of Aspergillus DNA in high-risk hematological patients. J. Clin. Microbiol. 2013, 51, 1445-1450.

90. De Pauw, B.; Walsh, T.J.; Donnelly, J.P.; Stevens, D.A.; Edwards, J.E.; Calandra, T.; Pappas, P.G.; Maertens, J.; Lortholary, O.; Kauffman, C.A.; et al. Revised definitions of invasive fungal disease from the European Organization for Research and Treatment of Cancer/Invasive Fungal Infections Cooperative Group and the National Institute of Allergy and Infectious Diseases Mycoses Study Group (EORTC/MSG) Consensus Group. Clin. Infect. Dis. 2008, 46, 1813-1821.

91. Blot, S.I.; Taccone, F.S.; van den Abeele, A.M.; Bulpa, P.; Meersseman, W.; Brusselaers, N.; Dimopoulos, G.; Paiva, J.A.; Misset, B.; Rello, J.; et al. A clinical algorithm to diagnose invasive pulmonary aspergillosis in critically ill patients. Am. J. Resp. Crit. Care Med. 2012, 186, 56-64.

92. Zaragoza, R.; Peman, J.; Salavert, M.; Viudes, A.; Solé, A.; Jarque, I.; Monte, E.; Romá, E.; Cantón, E. Multidisciplinary approach to the treatment of invasive fungal infections in adult patients. Prophylaxis, empirical, preemptive or targeted therapy, which is the best in the different hosts? Ther. Clin. Risk Manag. 2008, 4, 1261-1280.

93. Ribes, J.A.; Vanover-Sams, C.L.; Baker, D.J. Zygomycetes in human disease. Clin. Microbiol. Rev. 2000, 13, 236-301.

94. Petrikkos, G.; Skiada, A.; Lortholary, O.; Roilides, E.; Walsh, T.J.; Kontoyiannis, D.P. Epidemiology and clinical manifestations of mucormycosis. Clin. Infect. Dis. 2012, 54, S23-S34.

95. Andresen, D.; Donaldson, A.; Choo, L.; Knox, A.; Klaassen, M.; Ursic, C.; Vonthethoff, L.; Krilis, S.; Konecny, P. Multifocal cutaneous mucormycosis complicating polymicrobial wound infections in a tsunami survivor from Sri Lanka. Lancet 2005, 365, 876-878. 
96. Neblett Fanfair, R.; Benedict, K.; Bos, J.; Bennett, S.D.; Lo, Y.C.; Adebanjo, T.; Etienne, K.; Deak, E.; Derado, G.; Shieh, W.-J.; et al. Necrotizing cutaneous mucormycosis after a tornado in Joplin, Missouri, in 2011. N. Engl. J. Med. 2012, 367, 2214-2225.

97. Warkentien, T.; Rodriguez, C.; Lloyd, B.; Wells, J.; Weintrob, A.; Dunne, J.R.; Ganesan, A.; Li, P.; Bradley, W.; Gaskins, L.J.; et al. Invasive mold infections following combat-related injuries. Clin. Infect. Dis. 2012, 55, 1441-1449.

98. Maravi-Poma, E.; Rodriguez-Tudela, J.L.; de Jalon, J.G.; Manrique-Larralde, A.; Torroba, L.; Urtasun, J.; Salvador, B.; Montes, M.; Mellado, E.; Rodríguez-Albarrán, F.; et al. Outbreak of gastric mucormycosis associated with the use of wooden tongue depressors in critically ill patients. Intensiv. Care Med. 2004, 30, 724-728.

99. Lass-Florl, C. Zygomycosis: Conventional laboratory diagnosis. Clin. Microbiol. Infect. 2009, 15, 60-65.

100. Walsh, T.J.; Gamaletsou, M.N.; McGinnis, M.R.; Hayden, R.T.; Kontoyiannis, D.P. Early clinical and laboratory diagnosis of invasive pulmonary, extrapulmonary, and disseminated mucormycosis (zygomycosis). Clin. Infect. Dis. 2012, 54, S55-S60.

101. Millon, L.; Larosa, F.; Lepiller, Q.; Legrand, F.; Rocchi, S.; Daguindau, E.; Scherer, E.; Bellanger, A.P.; Leroy, J.; Grenouillet, F. Quantitative polymerase chain reaction detection of circulating DNA in serum for early diagnosis of mucormycosis in immunocompromised patients. Clin. Infect. Dis. 2013, 56, e95-e101.

102. Tawara, S.; Ikeda, F.; Maki, K.; Watabe, E.; Tawara, S.; Teratani1, N.; Goto1, T.; Tomishima, M.; Ohki, H.; Yamada, A.; et al. In vitro activities of a new lipopeptide antifungal agent, FK463, against a variety of clinically important fungi. Antimicrob. Agents Chemother. 2009, 44, 57-62.

103. Neumann, A.; Baginski, M.; Winczewski, S.; Czub, J. The effect of sterols on amphotericin B self-aggregation in a lipid bilayer as revealed by free energy simulations. Biophys. J. 2013, 104, $1485-1494$.

104. Ghannoum, M.A.; Rice, L.B. Antifungal agents: Mode of action, mechanisms of resistance, and correlation of these mechanisms with bacterial resistance. Clin. Microbiol. Rev. 1999, 12, 501-517.

105. Pfaller, M.A.; Messer, S.A.; Boyken, L.; Tendolkar, S.; Hollis, R.J.; Diekema, D.J. Geographic variation in the susceptibilities of invasive isolates of Candida glabrata to seven systemically active antifungal agents: A global assessment from the ARTEMIS Antifungal Surveillance Program conducted in 2001 and 2002. J. Clin. Microbiol. 2004, 42, 3142-3146.

106. Messer, S.A.; Jones, R.N.; Fritsche, T.R. International surveillance of Candida spp. and Aspergillus spp.: Report from the SENTRY Antimicrobial Surveillance Program (2003). J. Clin. Microbiol. 2006, 44, 1782-1787.

107. Sabatelli, F.; Patel, R.; Mann, P.A.; Mendrick, C.A.; Norris, C.C.; Hare, R.; Loebenberg, D.; Black, T.A.; McNicholas, P.M. In vitro activities of posaconazole, fluconazole, itraconazole, voriconazole, and amphotericin B against a large collection of clinically important molds and yeasts. Antimicrob. Agents Chemother. 2006, 50, 2009-2015.

108. Deray, G. Amphotericin B nephrotoxicity. J. Antimicrob. Chemother. 2002, 49, 37-41.

109. Blot, S.; Vandewoude, K. Management of invasive candidiasis in critically ill patients. Drugs 2004, 64, 2159-2175. 
110. Ostrosky-Zeichner, L.; Marr, K.A.; Rex, J.H.; Cohen, S.H. Amphotericin B: Time for a new "gold standard". Clin. Infect. Dis. 2003, 37, 415-425.

111. Mistro, S.; Maciel Ide, M.; de Menezes, R.G.; Maia, Z.P.; Schooley, R.T.; Badaro, R. Does lipid emulsion reduce amphotericin B nephrotoxicity? A systematic review and meta-analysis. Clin. Infect. Dis. 2012, 54, 1774-1777.

112. Shigemi, A.; Matsumoto, K.; Ikawa, K.; Yaji, K.; Shimodozono, Y.; Morikawa, N.; Takeda, Y.; Yamada, K. Safety analysis of liposomal amphotericin B in adult patients: Anaemia, thrombocytopenia, nephrotoxicity, hepatotoxicity and hypokalaemia. Int. J. Antimicrob. Agents 2011, 38, 417-420.

113. Adler-Moore, J.P.; Proffitt, R.T. Amphotericin B lipid preparations: What are the differences? Clin. Microb. Infect. 2008, 14, 25-36.

114. Pappas, P.G.; Kauffman, C.A.; Andes, D.; Benjamin, D.K., Jr.; Calandra, T.F.; Edwards, J.E., Jr. Clinical practice guidelines for the management of candidiasis: 2009 update by the Infectious Diseases Society of America. Clin. Infect. Dis. 2009, 48, 503-535.

115. Mills, E.J.; Perri, D.; Cooper, C.; Nachega, J.B.; Wu, P.; Tleyjeh, I.; Phillips, P. Antifungal treatment for invasive Candida infections: A mixed treatment comparison meta-analysis. Ann. Clin. Microbiol. Antimicrob. 2009, 8, 23-31.

116. Povoa, P.; Goncalves-Pereira, J. Treatment of candidemia in adult patients without neutropenia--an inconvenient truth. Crit. Care 2011, 15, 114.

117. Dreyfuss, D.; Ricard, J.D.; Gaudry, S. Amphotericin B deoxycholate for candidiasis in intensive care unit patients revisited: Medical, ethical, and financial implications. Am. J. Resp. Crit. Care Med. 2013, 187, 661-663.

118. Shoham, S.; Marwaha, S. Invasive fungal infections in the ICU. J. Intensiv. Care Med. 2010, 25, 78-92.

119. Baddley, J.W.; Patel, M.; Bhavnani, S.M.; Moser, S.A.; Andes, D.R. Association of fluconazole pharmacodynamics with mortality in patients with candidemia. Antimicrob. Agents Chemother. 2008, 52, 3022-3028.

120. Klepser, M.E.; Wolfe, E.J.; Jones, R.N.; Nightingale, C.H.; Pfaller, M.A. Antifungal pharmacodynamic characteristics of fluconazole and amphotericin B tested against Candida albicans. Antimicrob. Agents Chemother. 1997, 41, 1392-1395.

121. Playford, E.G.; Eggimann, P.; Calandra, T. Antifungals in the ICU. Curr. Opin. Infect. Dis. 2008, 21, 610-619.

122. Saari, T.I.; Laine, K.; Neuvonen, M.; Neuvonen, P.J.; Olkkola, K.T. Effect of voriconazole and fluconazole on the pharmacokinetics of intravenous fentanyl. Eur. J. Clin. Pharmacol. 2008, 64, 25-30.

123. Skrobik, Y.; Leger, C.; Cossette, M.; Michaud, V.; Turgeon, J. Factors predisposing to coma and delirium: Fentanyl and midazolam exposure, CYP3A5, ABCB1 and ABCG2 genetic polymorphisms and inflammatory factors. Crit. Care Med. 2013, 41, 999-1008.

124. Kullberg, B.J.; Sobel, J.D.; Ruhnke, M.; Pappas, P.G.; Viscoli, C.; Rex, J.H.; Cleary, J.D.; Rubinstein, E.; Church, L.W.P.; Brown, J.M.; et al. Voriconazole versus a regimen of amphotericin B followed by fluconazole for candidaemia in non-neutropenic patients: A randomised non-inferiority trial. Lancet 2005, 366, 1435-1442. 
125. Johnson, L.B.; Kauffman, C.A. Voriconazole: A new triazole antifungal agent. Clin. Infect. Dis. 2003, 36, 630-637.

126. Manavathu, E.K.; Cutright, J.L.; Chandrasekar, P.H. Organism-dependent fungicidal activities of azoles. Antimicrob. Agents Chemother. 1998, 42, 3018-3021.

127. Barry, A.L.; Brown, S.D. In vitro studies of two triazole antifungal agents (voriconazole [UK109,496] and fluconazole) against Candida species. Antimicrob. Agents Chemother. 1996, 40, 1948-1949.

128. Kauffman, C.A.; Zarins, L.T. In vitro activity of voriconazole against Candida species. Diagn. Microbiol. Infect. Dis. 1998, 31, 297-300.

129. Ally, R.; Schurmann, D.; Kreisel, W.; Carosi, G.; Aguirrebengoa, K.; Dupont, B.; Hodges, M.; Troke, P.; RomeroA, A.J. randomized, double-blind, double-dummy, multicenter trial of voriconazole and fluconazole in the treatment of esophageal candidiasis in immunocompromised patients. Clin. Infect. Dis. 2001, 33, 1447-1454.

130. Herbrecht, R.; Denning, D.W.; Patterson, T.F.; Bennett, J.E.; Greene, R.E.; Oestmann, J.W.; Kern, W.V.; Marr, K.A.; Ribaud, P.; Lortholary, O.; et al. Voriconazole versus amphotericin B for primary therapy of invasive aspergillosis. N. Engl. J. Med. 2002, 347, 408-415.

131. Neofytos, D.; Lombardi, L.R.; Shields, R.K.; Ostrander, D.; Warren, L.; Nguyen, M.H.; Thompson, C.B.; Marr, K.A. Administration of voriconazole in patients with renal dysfunction. Clin. Infect. Dis. 2012, 54, 913-921.

132. Oude Lashof, A.M.; Sobel, J.D.; Ruhnke, M.; Pappas, P.G.; Viscoli, C.; Schlamm, H.T.; Kullberg, B.J. Safety and tolerability of voriconazole in patients with baseline renal insufficiency and candidemia. Antimicrob. Agents Chemother. 2012, 56, 3133-3137.

133. Pascual, A.; Csajka, C.; Buclin, T.; Bolay, S.; Bille, J.; Calandra, T.; Marchetti, O. Challenging recommended oral and intravenous voriconazole doses for improved efficacy and safety: Population pharmacokinetics-based analysis of adult patients with invasive fungal infections. Clin. Infect. Dis. 2012, 55, 381-390.

134. Pascual, A.; Calandra, T.; Bolay, S.; Buclin, T.; Bille, J.; Marchetti, O. Voriconazole therapeutic drug monitoring in patients with invasive mycoses improves efficacy and safety outcomes. Clin. Infect. Dis. 2008, 46, 201-211.

135. Alvarez-Lerma, F.; Nicolas-Arfelis, J.M.; Rodriguez-Borregan, J.C.; Díaz-Regañón, J.; Sa-Borges, M.; García-López, F.; Allepuz-Palau, A. Clinical use and tolerability of voriconazole in the treatment of fungal infections in critically ill patients. J. Chemother. 2005, 17, 417-427.

136. Ullmann, A.J.; Lipton, J.H.; Vesole, D.H.; Chandrasekar, P.; Langston, A.; Tarantolo, S.R.; Greinix, H.; de Azevedo, W.M.; Reddy, V.; Boparai, N.; et al. Posaconazole or fluconazole for prophylaxis in severe graft-versus-host disease. N. Engl. J. Med. 2007, 356, 335-347.

137. Greenberg, R.N.; Mullane, K.; van Burik, J.A.; Raad, I.; Abzug, M.J.; Anstead, G.; Herbrecht, R.; Langston, A.; Marr, K.A.; Schiller, G.; et al. Posaconazole as salvage therapy for zygomycosis. Antimicrob. Agents Chemother. 2006, 50, 126-133.

138. Georgopapadakou, N.H. Update on antifungals targeted to the cell wall: Focus on beta-1,3-glucan synthase inhibitors. Expert Opin. Investig. Drugs 2001, 10, 269-280.

139. Mean, M.; Marchetti, O.; Calandra, T. Bench-to-bedside review: Candida infections in the intensive care unit. Crit. Care 2008, 12, 204. 
140. Stone, J.A.; Migoya, E.M.; Hickey, L.; Winchell, G.A.; Deutsch, P.J.; Ghosh, K.; Freeman, A.; Bi, S.; Desai, R.; Dilzer, S.C.; et al. Potential for interactions between caspofungin and nelfinavir or rifampin. Antimicrob. Agents Chemother. 2004, 48, 4306-4314.

141. Glockner, A. Treatment and prophylaxis of invasive candidiasis with anidulafungin, caspofungin and micafungin: Review of the literature. Eur. J. Med. Res. 2011, 16, 167-179.

142. Dimopoulos, G.; Antonopoulou, A.; Armaganidis, A.; Vincent, J.L. How to select an antifungal agent in critically ill patients. J. Crit. Care 2013, 28, 717-727.

143. Kett, D.; Shorr, A.F.; Reboli, A.C.; Reisman, A.L.; Biswas, P.; Schlamm, H.T. Anidulafungin compared with fluconazole in severely ill patients with candidaemia and other forms of invasive candidiasis: Support for the 2009 IDSA treatment guidelines for candidiasis. Crit. Care 2011, 15, R253.

144. Vermes, A.; Guchelaar, H.J.; Dankert, J. Flucytosine: A review of its pharmacology, clinical indications, pharmacokinetics, toxicity and drug interactions. J. Antimicrob. Chemother. 2000, 46, 171-179.

145. Matthews, R.C.; Rigg, G.; Hodgetts, S.; Carter, T.; Chapman, C.; Gregory, C.; Illidge, C.; Burnie, J. Preclinical assessment of the efficacy of mycograb, a human recombinant antibody against fungal HSP90. Antimicrob. Agents Chemother. 2003, 47, 2208-2216.

146. Morrell, M.; Fraser, V.J.; Kollef, M.H. Delaying the empiric treatment of candida bloodstream infection until positive blood culture results are obtained: A potential risk factor for hospital mortality. Antimicrob. Agents Chemother. 2005, 49, 3640-3645.

147. Garey, K.W.; Rege, M.; Pai, M.P.; Mingo, D.E.; Suda, K.J.; Turpin, R.S.; Bearden, D.T. Time to initiation of fluconazole therapy impacts mortality in patients with candidemia: A multi-institutional study. Clin. Infect. Dis. 2006, 43, 25-31.

148. Garrouste-Orgeas, M.; Timsit, J.F.; Tafflet, M.; Misset, B.; Zahar, J.R.; Soufir, L.; Lazard, T.; Jamali, S.; Mourvillier, B.; Cohen, Y.; et al. Excess risk of death from intensive care unit-acquired nosocomial bloodstream infections: A reappraisal. Clin. Infect. Dis. 2006, 42, 1118-1126.

149. Skrobik, Y.; Laverdiere, M. Why Candida sepsis should matter to ICU physicians. Crit. Care Clin. 2013, 29, 853-864.

150. Bow, E.; Evans, G.; Fuller, J.; Laverdière, M.; Rotstein, C.; Rennie, R.; Shafran, S.D.; Sheppard, D.; Carle, S.; Phillips, P.; et al. Canadian clinical practice guidelines for invasive candidiasis in adults. Can. J. Infect. Dis. Med. Microbiol. 2010, 21, e122-e150.

151. Cornely, O.A.; Bassetti, M.; Calandra, T.; Garbino, J.; Kullberg, B.J.; Lortholary, O.; Meersseman, W.; Akova, M.; Arendrup, M.C.; Arikan-Akdagli, S.; et al. ESCMID guidelines for the diagnosis and management of Candida diseases 2012: Non- neutropenic adult patients. Clin. Microbiol. Infect. 2012, 18, 19-37.

152. Kullberg, B.J.; Verweij, P.E.; Akova, M.; Arendrup, M.C.; Bille, J.; Calandra, T.; Cuenca-Estrella, M.; Herbrecht, R.; Jacobs, F.; Kalin, M.; et al. European expert opinion on the management of invasive candidiasis in adults. Clin. Microbiol. Infect. 2011, 17, 1-12.

153. Limper, A.H.; Knox, K.S.; Sarosi, G.A.; Ampel, N.M.; Bennett, J.E.; Catanzaro, A.; Davies, S.F.; Dismukes, W.E.; Hage, C.A.; Marr, K.A.; et al. An official American Thoracic Society statement: Treatment of fungal infections in adult pulmonary and critical care patients. Am. J. Resp. Crit. Care Med. 2011, 183, 96-128. 
154. Ruhnke, M.; Rickerts, V.; Cornely, O.; Buchheidt, D.; Glöckner, A.; Heinz, W.; Höhl, R.; Horré, R.; Karthaus, M.; Kujath, P.; Willinger, B.; et al. Diagnosis and therapy of Candida infections: Joint recommendations of the German Speaking Mycological Society and the Paul-Ehrlich-Society for Chemotherapy. Mycoses 2011, 54, 279-310.

155. Labbe, A.C.; Pepin, J.; Patino, C.; Castonguay, S.; Restieri, C.; Laverdiere, M. A single-centre 10-year experience with Candida bloodstream infections Can. J. Infect. Dis. Med. Microbiol. 2009, 20, 45-50.

156. Pfaller, M.A.; Messer, S.A.; Moet, G.J.; Jones, R.N.; Castanheira, M. Candida bloodstream infections: Comparison of species distribution and resistance to echinocandin and azole antifungal agents in Intensive Care Unit (ICU) and non-ICU settings in the SENTRY Antimicrobial Surveillance Program (2008-2009). Int. J. Antimicrob. Agents 2011, 38, 65-69.

157. Nucci, M.; Anaissie, E.; Betts, R.F.; Dupont, B.F.; Wu, C.; Buell, D.N.; Kovanda, L.; Lortholary, O. Early removal of central venous catheter in patients with candidemia does not improve outcome: Analysis of 842 patients from 2 randomized clinical trials. Clin. Infect. Dis. 2010, 51, 295-303.

158. Walsh, T.J.; Rex, J.H. All catheter-related candidemia is not the same: Assessment of the balance between the risks and benefits of removal of vascular catheters. Clin. Infect. Dis. 2002, 34, 600-602.

159. Ostrosky-Zeichner, L. Combination antifungal therapy: A critical review of the evidence. Clin. Microbiol. Infect. 2008, 14, 65-70.

160. Senn, L.; Eggimann, P.; Ksontini, R.; Pascual, A.; Demartines, N.; Bille, J.; Calandra, T.; Marchetti, O. Caspofungin for prevention of intra-abdominal candidiasis in high-risk surgical patients. Intensiv. Care Med. 2009, 35, 903-908.

161. Silvestri, L.; van Saene, H.K.; Milanese, M.; Gregori, D. Impact of selective decontamination of the digestive tract on fungal carriage and infection: Systematic review of randomized controlled trials. Intensiv. Care Med. 2005, 31, 898-910.

162. Garbino, J.; Lew, D.P.; Romand, J.A.; Hugonnet, S.; Auckenthaler, R.; Pittet, D. Prevention of severe Candida infections in nonneutropenic, high-risk, critically ill patients: A randomized, double-blind, placebo-controlled trial in patients treated by selective digestive decontamination. Intensiv. Care Med. 2002, 28, 1708-1717.

163. Pelz, R.K.; Hendrix, C.W.; Swoboda, S.M.; Diener-West, M.; Merz, W.G.; Hammond, J.; Lipsett, P.A. Double-blind placebo-controlled trial of fluconazole to prevent candidal infections in critically ill surgical patients. Ann. Surg. 2001, 233, 542-548.

164. Swoboda, S.M.; Merz, W.G.; Lipsetta, P.A. Candidemia: The impact of antifungal prophylaxis in a surgical intensive care unit. Surg. Infect. 2003, 4, 345-354.

165. Eggimann, P.; Francioli, P.; Bille, J.; Schneider, R.; Wu, MM.; Chapuis, G.; Chiolero, R. Fluconazole prophylaxis prevents intra-abdominal candidiasis in high-risk surgical patients. Crit. Care Med. 1999, 27, 1066-1072.

166. Grewe, M.; Tsiotos, G.G.; Luque de-Leon, E.; Sarr, M.G. Fungal infection in acute necrotizing pancreatitis. J. Am. Coll. Surg. 1999, 188, 408-414.

167. De Waele, J.J.; Vogelaers, D.; Blot, S.; Colardyn, F. Fungal infections in patients with severe acute pancreatitis and the use of prophylactic therapy. Clin. Infect. Dis. 2003, 37, 208-213. 
168. Cruciani, M.; de Lalla, F.; Mengoli, C. Prophylaxis of Candida infections in adult trauma and surgical intensive care patients: A systematic review and meta-analysis. Intensiv. Care Med. 2005, 31, 1479-1487.

169. Playford, E.G.; Webster, A.C.; Sorrell, T.C.; Craig, J.C. Antifungal agents for preventing fungal infections in non-neutropenic critically ill and surgical patients: Systematic review and meta-analysis of randomized clinical trials. J. Antimicrob. Chemother. 2006, 57, 628-638.

170. Shorr, A.F.; Chung, K.; Jackson, W.L.; Waterman, P.E.; Kollef, M.H. Fluconazole prophylaxis in critically ill surgical patients: A meta-analysis. Crit. Care Med. 2005, 33, 1928-1935.

171. Vardakas, K.Z.; Samonis, G.; Michalopoulos, A.; Soteriades, E.S.; Falagas, M.E. Antifungal prophylaxis with azoles in high-risk, surgical intensive care unit patients: A meta-analysis of randomized, placebo-controlled trials. Crit. Care Med. 2006, 34, 1216-1224.

172. Lam, S.W.; Eschenauer, G.A.; Carver, P.L. Evolving role of early antifungals in the adult intensive care unit. Crit. Care Med. 2009, 37, 1580-1593.

173. Piarroux, R.; Grenouillet, F.; Balvay, P.; Tran, V.; Blasco, G.; Millon, L, Boillot, A. Assessment of preemptive treatment to prevent severe candidiasis in critically ill surgical patients. Crit. Care Med. 2004, 32, 2443-2449.

174. Hanson, K.E.; Pfeiffer, C.D.; Lease, E.D.; Balch, A.H.; Zaas, A.K.; Perfect, J.R.; Alexander, B.D. Beta-D-glucan surveillance with preemptive anidulafungin for invasive candidiasis in intensive care unit patients: A randomized pilot study. PloS one 2012, 7, e42282.

175. Schuster, M.G.; Edwards, J.E., Jr.; Sobel, J.D.; Darouiche, R.O.; Karchmer, A.W.; Hadley, S.; Slotman, G.; Panzer, H.; Biswas, P.; Rex, J.H. Empirical fluconazole versus placebo for intensive care unit patients: A randomized trial. Ann. Intern. Med. 2008, 149, 83-90.

176. Golan, Y. Empiric anti-Candida therapy for patients with sepsis in the ICU: How little is too little? Crit. Care 2009, 13, 180.

177. Cornely, O.A.; Maertens, J.; Bresnik, M.; Ebrahimi, R.; Dellow, E.; Herbrecht, R.; Donnelly, J.P. Efficacy outcomes in a randomised trial of liposomal amphotericin B based on revised EORTC/MSG 2008 definitions of invasive mould disease. Mycoses 2011, 54, e449-e455.

178. Walsh, T.J.; Anaissie, E.J.; Denning, D.W.; Herbrecht, R.; Kontoyiannis, D.P.; Marr, K.A.; Morrison, V.A.; Segal, B.H.; Steinbach, W.J.; Stevens, D.A.; et al. Treatment of aspergillosis: Clinical practice guidelines of the Infectious Diseases Society of America. Clin. Infect. Dis. 2008, 46, 327-360.

179. Maertens, J.; Raad, I.; Petrikkos, G.; Boogaerts, M.; Selleslag, D.; Petersen, F.B.; Sable, C.A.; Kartsonis, N.A.; Ngai, A.; Taylor, A.; et al. Efficacy and safety of caspofungin for treatment of invasive aspergillosis in patients refractory to or intolerant of conventional antifungal therapy. Clin. Infect. Dis. 2004, 39, 1563-1571.

180. Sutton, D.A.; Sanche, S.E.; Revankar, S.G.; Fothergill, A.W.; Rinaldi, M.G. In vitro amphotericin B resistance in clinical isolates of Aspergillus terreus, with a head-to-head comparison to voriconazole. J. Clin. Microbiol. 1999, 37, 2343-2345.

181. Alcazar-Fuoli, L.; Mellado, E.; Alastruey-Izquierdo, A.; Cuenca-Estrella, M.; Rodriguez-Tudela, J.L. Aspergillus section Fumigati: Antifungal susceptibility patterns and sequence-based identification. Antimicrob. Agents Chemother. 2008, 52, 1244-1251. 
182. Kousha, M.; Tadi, R.; Soubani, A.O. Pulmonary aspergillosis: A clinical review. Eur. Resp. J. 2011, 20, 156-174.

183. Safdar, A. Strategies to enhance immune function in hematopoietic transplantation recipients who have fungal infections. Bone Marrow Transplant. 2006, 38, 327-337.

184. Price, T.H.; Bowden, R.A.; Boeckh, M.; Bux, J.; Nelson, K.; Liles, W.C.; Dale, D.C. Phase I/II trial of neutrophil transfusions from donors stimulated with G-CSF and dexamethasone for treatment of patients with infections in hematopoietic stem cell transplantation. Blood 2000, 95, 3302-3309.

185. Ullmann, A.J.; Cornely, O.A. Antifungal prophylaxis for invasive mycoses in high risk patients. Curr. Opin. Infect. Dis. 2006, 19, 571-576.

186. Kontoyiannis, D.P.; Lewis, R.E. How I treat mucormycosis. Blood 2011, 118, 1216-1224.

(C) 2014 by the authors; licensee MDPI, Basel, Switzerland. This article is an open access article distributed under the terms and conditions of the Creative Commons Attribution license (http://creativecommons.org/licenses/by/3.0/). 